\title{
Design procedure and experimental study on fibre reinforced concrete segmental rings for vertical shafts
}

\author{
Lin Liao $^{\text {a,b }}$, Albert de la Fuente ${ }^{\text {a, }}$, Sergio Cavalaro ${ }^{\text {a }}$, Antonio Aguado ${ }^{\text {a }}$ \\ $a$ Civil and Environmental Engineering Department, Universitat Politècnica de Catalunya (UPC \\ BarcelonaTECH), Jordi Girona 1-3, 08034, Barcelona, Spain. \\ b Department of Underground Engineering, Taiyuan University of Technology, 79 Yingze West \\ Street, 030024 Taiyuan, China \\ * Corresponding author. Tel.: +34-93-401-65-15. E-mail: albert.de.la.fuente@upc.edu
}

Keywords: MC 2010; optimal design; vertical shafts; precast segments; FRC

\begin{abstract}
Structural fibres are used to replace partially or totally the passive reinforcement in precast concrete segments for tunnel linings constructed with TBM, showing several advantages. Fibre reinforced concrete (FRC) could also be applied with similar benefits to vertical shafts. However, to the author's knowledge, this material has not been used in such application yet. The Model Code 2010 gathers an approach for the design of FRC structural elements. This approach should be adapted according to the structural needs of precast segment, for which the transient load stages are often the most critical and specific ductility requirements should be established. The objective of this paper is twofold: propose a general analytical formulation to assess the minimum mechanical requirements that FRC must fulfil in case of partial or complete substitution of the steel rebars and confirm that it is possible to replace the rebars by using fibres in vertical shaft linings. First, the general analytical formulation is proposed. Then, the segments of the Montcada vertical shaft (Barcelona) are redesigned considering the total substitution of the traditional reinforcement by fibres. Finally, two full-scale tests of the FRC precast segments were performed to verify the suitability of the analytical formulation proposed.
\end{abstract}

\section{INTRODUCTION}

Structural fibres are commonly used in precast segments for the lining of tunnels constructed with tunnel boring machines (TBM). These structures usually remain under compression in service, presenting tensile stresses primarily during transient stages (demoulding, storage, transport, handling, and installation). Under these conditions, the partial or even the complete replacement of traditional bar reinforcement by an adequate amount of structural fibres becomes attractive from an economic and technic standpoint.

Currently, several codes and guidelines include fibre reinforced concrete (FRC) as a structural material; highlighted among them the MC 2010 [1]. Furthermore, many experimental 
campaigns [2-9] from the literature (Table 1) have focused on the production, full-scale bending tests, and numeric simulations of segments made of concrete with compressive strengths fc ranging from 20 to $150 \mathrm{~N} / \mathrm{mm} 2$ and structural fibre contents $(\mathrm{Cf})$ ranging from 30 to $236 \mathrm{~kg} / \mathrm{m} 3$. Moreover [10-16] present a set of real experiences in tunnels constructed with TBM in which FRC is used. These experiences have promoted the application of FRC, demonstrating that the material is competitive at the structural level compared with other traditional solution

Table 1. Experimental campaigns and numerical simulations collected from the scientific literature regarding FRC segments for tunnels created with a TBM.

\begin{tabular}{|c|c|c|c|c|c|c|c|c|}
\hline \multirow{2}{*}{ Elements } & $\mathbf{f}_{\mathrm{c}}$ & Dimensions & \multirow{2}{*}{ Material } & $C_{f}$ & \multirow{2}{*}{$\Phi_{\mathrm{f}} / \lambda_{\mathrm{f}}$} & \multirow{2}{*}{ No } & \multirow{2}{*}{ Num. Sim. } & \multirow{2}{*}{ Ref } \\
\hline & $(\mathrm{MPa})$ & $(\mathrm{mm})$ & & $\left(\mathrm{kg} / \mathrm{m}^{3}\right)$ & & & & \\
\hline \multirow{2}{*}{$\begin{array}{l}\text { PS } \\
\text { (RT) }\end{array}$} & 75 & \multirow{2}{*}{$3640 \times 1500 \times 200$} & SFRC & 40 & $0.35 / 30$ & 1 & \multirow{2}{*}{ None } & \multirow{2}{*}[2]{} \\
\hline & 45 & & $\mathrm{RC}$ & --- & --- & 1 & & \\
\hline \multirow{3}{*}{$\begin{array}{l}\text { PS } \\
\text { (RP) }\end{array}$} & \multirow{3}{*}{60} & \multirow{3}{*}{$2359 \times 1400 \times 350$} & $\mathrm{PC}$ & --- & --- & 3 & \multirow{3}{*}{ None } & \multirow{3}{*}[3]{} \\
\hline & & & \multirow{2}{*}{ SFRC } & 30 & \multirow{2}{*}{$0.75 / 60$} & 3 & & \\
\hline & & & & 40 & & 3 & & \\
\hline \multirow{2}{*}{$\begin{array}{l}\mathrm{PS} \\
\text { (RT) }\end{array}$} & \multirow{2}{*}{45} & \multirow{2}{*}{$2406 \times 900 \times 200$} & $\mathrm{RC}$ & --- & --- & 1 & \multirow{2}{*}{ None } & \multirow{2}{*}[4]{} \\
\hline & & & SFRC & 20 & $0.55 / 35$ & 1 & & \\
\hline \multirow{2}{*}{$\begin{array}{l}\text { PS } \\
\text { (MT) }\end{array}$} & \multirow{2}{*}{60} & \multirow{2}{*}{$4700 \times 1800 \times 350$} & \multirow{2}{*}{ SFRC } & 40 & \multirow{2}{*}{$0.75 / 60$} & 2 & \multirow{2}{*}{ None } & \multirow{2}{*}[5]{} \\
\hline & & & & 50 & & 2 & & \\
\hline \multirow{3}{*}{$\begin{array}{l}\text { PS } \\
\text { (MT) }\end{array}$} & & & $\mathrm{SFRC}+\mathrm{RC}$ & 30 & & 2 & & \\
\hline & 60 & $4700 \times 1800 \times 350$ & SEPC & 45 & $1.0 / 50$ & 2 & Yes & {$[6]$} \\
\hline & & & DITC & 60 & & 2 & & \\
\hline & & & PC & --- & --- & 1 & & \\
\hline & & & SFRC & 40 & $0.8 / 60$ & 1 & & \\
\hline & & & $\mathrm{PC}$ & -- & -- & 1 & & \\
\hline PS & 20 & Semi-circle & SFRC & 40 & $0.8 / 60$ & 1 & & \\
\hline (MT) & 20 & $9700 \times 1000 \times 300$ & $\mathrm{PC}$ & --- & --- & 1 & Yes & {$[7]$} \\
\hline & & & SFRC & 40 & $0.8 / 30$ & 1 & & \\
\hline & & & $\mathrm{PC}$ & -- & -- & 1 & & \\
\hline & & & SFRC & 40 & $0.8 / 60$ & 1 & & \\
\hline & 66 & 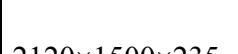 & $\mathrm{RC}$ & --- & --- & 1 & & \\
\hline & 68 & $2120 \times 1500 \times 235$ & SFRC & 120 & $0.75 / 60$ & 1 & Nomo & \\
\hline PS & 66 & $2180 \times 1500 \times 225$ & $\mathrm{RC}$ & --- & --- & 1 & None & \\
\hline (RP) & 68 & $3180 \times 1500 \times 235$ & $\mathrm{SFRC}+\mathrm{PF}$ & 120 & $0.75 / 60$ & 1 & & {$[8]$} \\
\hline & 140 & $1000 \times 500 \times 100$ & UHPC & --- & --- & 1 & Y & \\
\hline & 150 & $1000 \times 500 \times 100$ & UHPFRC & 236 & $0.2 / 80$ & 1 & Yes & \\
\hline $\begin{array}{l}\text { PS } \\
\text { (MT) }\end{array}$ & 68 & $2438 \times 1500 \times 235$ & SFRC & 57 & $0.75 / 60$ & 6 & Yes & {$[9]$} \\
\hline
\end{tabular}


PS: precast segment; RT: Road Tunnel; RP: Research Project; MT: Metro Tunnel; fc: concrete compressive strength; SFRC: Steel Fibre Reinforced Concrete; RC: Reinforced Concrete; UHPC: Ultra High Performance Concrete; UHPFRC: UltraHigh Fibre Reinforced Concrete; PF: Plastic Fibres; $\Phi_{\mathrm{f}}$ : cross section diameter of the fibres; $\lambda_{\mathrm{f}}$ : aspect ratio of the fibres

Until now, the design of FRC segments has been addressed by means of numerical methods [3,17-27]. To the authors' best knowledge, no analytical expression that describes the design of segments reinforced only with fibres or with hybrid reinforcement (fibre + bars) is found in the literature. Furthermore, the authors have been unable to find any reference in which these types of segments are used in vertical shafts constructed with a vertical shaft machine (VSM). Like in many tunnels, in this case the segments are generally subjected to reduced stresses during the transitional phases and compression predominates during service. Therefore, despite the absence of previous experiences, the use of structural fibres instead of bars may also be competitive

The aim of this study is to provide a response to the two absences mentioned in the previous paragraph. On one hand, the objective is to demonstrate that the complete replacement of the bar reinforcement by fibres is also possible in shaft linings constructed with VSM. On the other hand, the objective is to propose an analytical and general formulation to assess the minimum mechanical requirements that the FRC must fulfil in elements with complete or partial substitutions of the traditional reinforcement.

First, the analytical formulation based on the MC 2010 is proposed for the structural design of FRC segments. This formulation is then applied to the redesign of the segments from Montcada Shaft, which was originally conceived with traditional reinforcement. After that, in the context of full-scale construction work (Montcada Shaft, Barcelona) and a research project, a characterization campaign of conventional and self-compacting concretes reinforced with fibre quantities (Cf) between 30 and $60 \mathrm{~kg} / \mathrm{m} 3$ was performed to evaluate the optimum amount for the complete removal of the traditional reinforcement. Finally, an experimental campaign of full-scale segments subjected to bending was performed with both concrete types to verify the ductile behaviour until failure. This study widens the field of application of FRC, demonstrating the feasibility of a new use. Moreover, it shows new formulations that might support engineers towards the optimal structural design of this type of structures or others constructed with FRC.

\section{BRIEF OVERVIEW ON FRC DESIGN}

The most common METHOD to characterize post-cracking behaviour of FRC is the three-point test for prismatic specimens with dimensions of $150 \times 150 \times 550 \mathrm{~m}^{3}$, which are notched at the centre (Figure 1a) according to the EN 14651:2005 standard [28]. During the test, the vertical displacement is controlled and both the load $F$ with the crack mouth opening displacement (CMOD) are mesured. 

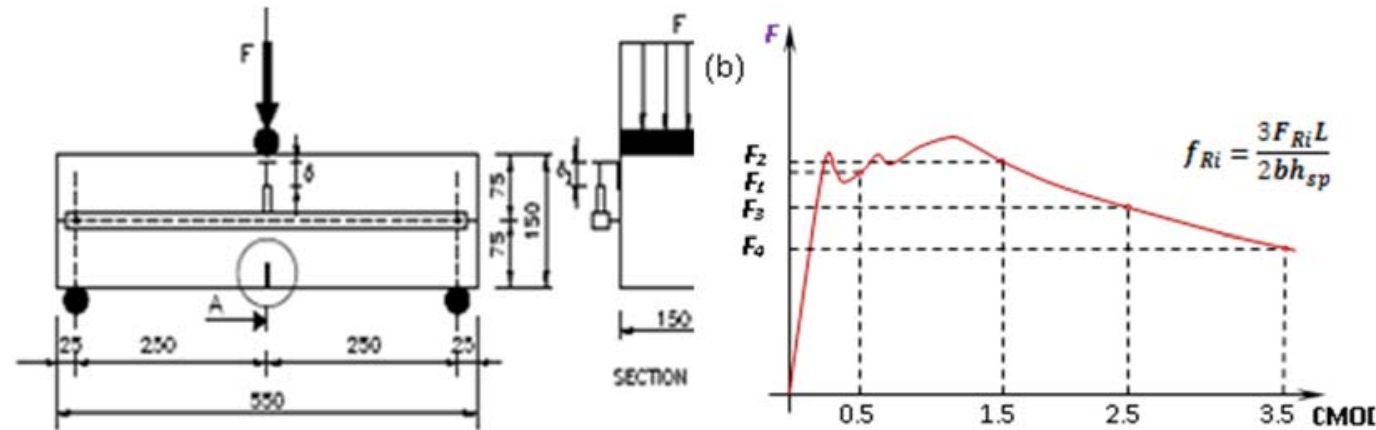

Figure 1. Three-point test in notched prismatic beams: (a) test configuration (mm) and (b) $\boldsymbol{F}-\boldsymbol{C M O D}$ generic curve

The F-CMOD curve obtained (Fig. 1b) may be used to deduce the tensile constitutive law $\sigma-\varepsilon$ of the FRC. The stresses $\sigma$ are obtained from the residual tensile strength fRi. The classification proposed in MC 2010 is based on the characteristic values of the residual tensile strength for $\mathrm{CMOD}=0.5 \mathrm{~mm}(\mathrm{fR} 1 \mathrm{k})$ and $\mathrm{CMOD}=2.5 \mathrm{~mm}(\mathrm{fR} 3 \mathrm{k})$. In this regard, the FRC strength class is specified using fR1k to represent the strength interval and the letter (a, b, c, d, or e) to represent the $\mathrm{fR} 3 \mathrm{k} / \mathrm{fR} 1 \mathrm{k}$ ratio. The strength interval $\mathrm{fR} 1 \mathrm{k}$ is established by using a number from the following series: $1.0-1.5-2.0-2.5-3.0-4.0-4.5-5.0-6.0-7.0-8.0$ in $\mathrm{N} / \mathrm{mm} 2$.

The $\mathrm{fR} 3 \mathrm{k} / \mathrm{fR} 1 \mathrm{k}$ ratios are in accordance with the following series: a) if $0.5 \leq \mathrm{fR} 3 \mathrm{k} / \mathrm{fR} 1 \mathrm{k}<0.7$; b) if $0.7 \leq \mathrm{fR} 3 \mathrm{k} / \mathrm{fR} 1 \mathrm{k}<0.9$; c) if $0.9 \leq \mathrm{fR} 3 \mathrm{k} / \mathrm{fR} 1 \mathrm{k}<1.1$; d) if $1.1 \leq \mathrm{fR} 3 \mathrm{k} / \mathrm{fR} 1 \mathrm{k}<1.3$; and e) if $\mathrm{f}$ $\mathrm{R} 3 \mathrm{k} / \mathrm{fR} 1 \mathrm{k} \geq 1.3$. In addition to that, the MC 2010 establishes that when the goal is to replace either partially or completely the traditional reinforcement with an equivalent quantity of structural fibres in ultimate limit state (ULS), the following conditions must be satisfied: $\mathrm{fR} 1 \mathrm{k} / \mathrm{fLk}>0.4$ and fR $3 \mathrm{k} / \mathrm{fR} 1 \mathrm{k}>0.5$.

\section{DESIGN OF ELEMENTS SUBJECTED TO REDUCED STRESSES}

\subsection{Introduction}

The classical design philosophy of reinforced concrete structures (also for prestressed structures) aims to guarantee ductile behaviour close to failure. In this regard, in sections where the applied bending moment $(\mathrm{M})$ is lower than the cracking bending moment (Mcr), a minimum amount of traditional reinforcement (As,min) is needed to ensure that the ultimate bending moment (Mu) is equal to or greater $\tan \operatorname{Mcr}(\mathrm{Mu} \geq \mathrm{Mcr}$; see Fig. 2). This means that the strength capacity of the concrete matrix is maintained during the post-cracking phase 


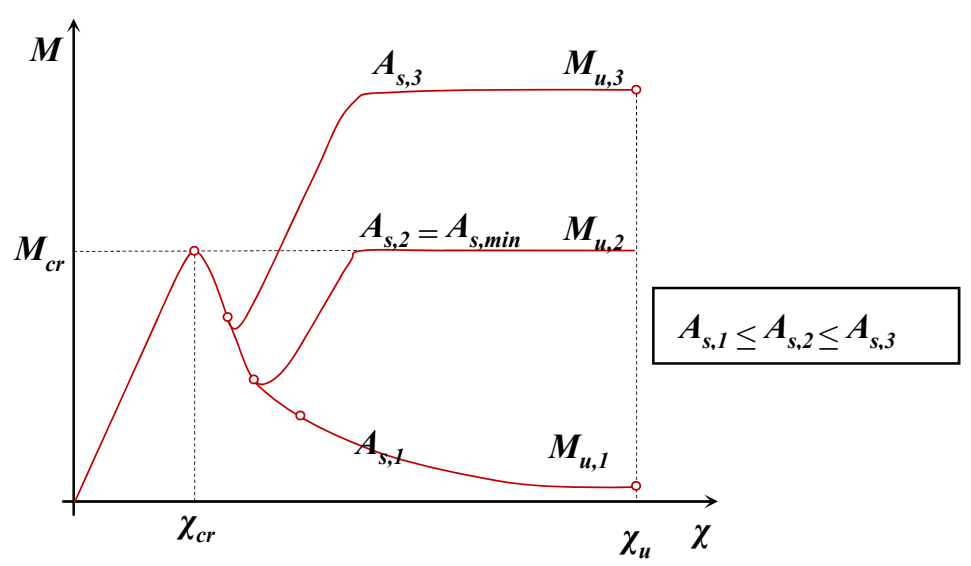

Figure 2. Moment $\boldsymbol{M}$-Curvature $\chi$ diagram to illustrate sectional response as a function of the degree of reinforcement.

This approach has been adopted in the MC 2010 and in other national codes to evaluate As,min. Eq. (1) shows the minimum amount of traditional reinforcement needed to fulfil the ductility requirements in rectangular sections. This equation is derived by matching the mean value of Mcr (Mcrm) with Mu, assuming that in ULS the arm (z) equals 0.8 of the height (h), the distance to the gravity centre of the bars in tension (d) equals $0.9 \mathrm{of} h$, and the partial safety factor of the steel bar $(\gamma \mathrm{s})$ is 1.15. In this regard, as discussed in [29], adopting mean values of Mcr leads to As, min on the safe side.

$$
A_{s, \min }=0.26 \frac{f_{c t m, f l}}{f_{y k}} b d
$$

In the FRC elements, assuming mean values of $\boldsymbol{M}_{\boldsymbol{c}}$ for this type of approach usually leads to high minimum fibres contents $\left(\boldsymbol{C}_{f, \text { min }}\right)$, which could be unfeasible at a technical and economic standpoint. In the case of segments for tunnel linings, an extensive discussion of this issue may be found in [30]. Tacking that into account, the design values of $\boldsymbol{M}_{c r}$ and tension strength in flexion $f_{c t, f l}$ ( $\boldsymbol{M}_{c r d}$ and $f_{c t d, f l}$, respectively) are assumed for the evaluation of $\boldsymbol{A}_{\boldsymbol{s}, \min }$ and $\boldsymbol{f}_{R 3 k, \min }$ to ensure the ductility of the segment in case such the design value of the moment $\left(\boldsymbol{M}_{\boldsymbol{d}}\right)$ exceeds $M_{\text {crd }}$.

\subsection{Formula to evaluate minimum reinforcement requirements}

In contrast to bar-reinforced concrete sections (for which there are formulas, such as Eq. 1 to evaluate $\left.A_{s, \text { min }}\right)$, for FRC sections and sections with hybrid reinforcement $\left(A_{s}+C_{f}\right)$, there are no analytical formulas to obtain values of $f_{R 3 \min }$ to satisfy the minimum ductility requirements. In this regard, the recommendations proposed in MC 2010 as well as in the classical approach, which consists of ensure that $\boldsymbol{M}_{u} \geq \boldsymbol{M}_{c r, d}$.

A rectangular section with dimensions of $b$ and $h$ with a hybrid reinforcement, which is represented in Figure 3, is considered. This would respond to a section of an FRC segment with 
localised reinforcement to confine the concrete during the jack thrust phase and to control possible cracking due to bursting and splitting [31-37].
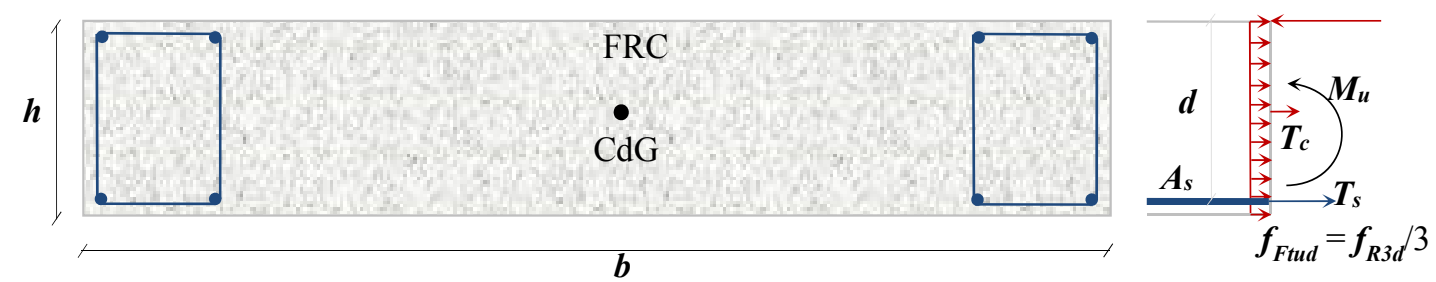

Figure 3. Cross-section of a segment with hybrid reinforcement $\left(\boldsymbol{A}_{\boldsymbol{s}}+\boldsymbol{C}_{f}\right)$.

Notice that the longitudinal bars and the fibres contribute to the flexural strength of the crosssection. The fR3 required will depend on the amount of traditional reinforcement used. To assess the characteristic value of $\mathrm{fR} 3$ (fR $3 \mathrm{k}$ ), a sectional analysis is proposed and the following hypotheses are assumed.

- The behaviour of FRC subjected to tensile stresses is simulated through the perfect plastic constitutive diagram proposed in MC 2010 and defined by the design value of the ultimate tensile residual strength of the material ( $\left.f_{\mathrm{Ftud}}\right)$ that should equal $f_{R 3 d} / 3$. The value of $\mathrm{fR} 3 \mathrm{~d}$ should be obtained by the division of the corresponding characteristic value (fRk3) by the partial safety factor for the FRC under tensile forces $\left(\gamma_{\mathrm{FRC}}\right)$.

- Since sections are weakly reinforced, the neutral line in bending for ULS is located near the upper fibre. The same is true for the resultant forcé $\mathrm{Cc}$ of the compressive stresses, which should also be concentrated in the upper fibre.

- The passive reinforcement reaches the yielding limit and develops tensile forcé $T_{s}=$ $A_{s} \cdot f_{y d}$ where $f_{y d}=f_{y k} / \gamma_{s}$ and $f_{y k}\left(f_{y d}\right.$ and $\left.f_{y d}\right)$ are the characteristic and design values of the elastic limit of steel, respectively. The reinforcement near the upper fibre is not taken into account in the analysis. This hypothesis is on the safe side.

The equilibrium equations of the horizontal loads (Eq. 2) and of the moments with respect to the section centre of gravity (Eq. 3) are imposed. By combining Eqs. 2 and 3, Eq. 4 is obtained.

$$
C_{c}-T_{s}-T_{f}=0
$$

$M_{u}=C_{c} \frac{h}{2}+T_{s}\left(d-\frac{h}{2}\right)$

$M_{u}=f_{\text {Ftud }} \frac{b h^{2}}{2}+A_{s} f_{y d} d$

Considering that for all the loading stages $\boldsymbol{M}_{\boldsymbol{d}} \leq \boldsymbol{M}_{\text {crd }}$ only a minimum amount of reinforcement is required to ensure ductile failure. In other words, the condition of $M_{u} \geq M_{\text {crd }}$ should be imposed. $\boldsymbol{M}_{c r d}$ can be evaluated by a linear elastic calculation that, for rectangular sections, in mathematically represented trough Eq. 5. 


$$
M_{c r d}=\frac{b h^{2}}{6} f_{c t d, f l}
$$

By combining Eqs. (4) and (5) and considering the relationship $\xi=d / h$ and $\rho_{s}=A_{s} / A_{c}$, (the geometric quantity of passive reinforcement). Eq. 6 , is obtained, to asses $f_{R 3 k}$. In this equation, $\gamma_{c}$ is the partial safety factor for concrete

$$
f_{R 3 k \geq} \frac{\gamma_{H R F}}{\gamma_{c}}\left(1-6 \rho_{s} \frac{\frac{f_{y k}}{\gamma_{s}}}{f_{c k, f l}} \xi\right) f_{c k, f l}
$$

The minimum geometric amount of reinforcement for sections only reinforced with traditional reinforcement $\left(\rho_{s, \min }\right)$ can be evaluated with Eq. 7. This equation is derived by matching the $\boldsymbol{M}_{u}$ (obtained through Eq. 4 for $\boldsymbol{f}_{\text {Ftud }}=0$ and $\boldsymbol{C}_{\boldsymbol{f}}=0$ ) with $\boldsymbol{M}_{\text {crd }}$ (Eq. 5). By combining Eqs. 6 and 7 , a closed expression is achieved for the ratio $f_{R 3 k} / f_{c t k, f l}$ (Eq. 8) of FRC. Notice that the latter depends on the geometric amount of traditional reinforced $\left(\rho_{s}\right)$ used.

$$
\begin{gathered}
\rho_{s, \min }=\frac{h}{6 d} \frac{\frac{f_{c t k, f l}}{\frac{\gamma_{c}}{f_{y k}}}}{\gamma_{s}}=\frac{1}{6 \xi} \frac{f_{c t k, f l}}{f_{y k}} \frac{\gamma_{s}}{\gamma_{c}} \\
f_{R 3 k} / f_{c t k, f l} \geq \frac{\gamma_{H R F}}{\gamma_{c}}\left(1-\frac{\rho_{s}}{\rho_{s, \min }}\right)
\end{gathered}
$$

Figure 4 shows how the ratio $f_{\mathrm{R} 3 \mathrm{k}} / f_{\mathrm{ctk}}$, fl varies with the ratio $\rho_{\mathrm{s}} / \rho_{\mathrm{s}, \min }$. The curve obtained was calculated by assuming that $\gamma_{\mathrm{FRC}}$ and $\gamma_{\mathrm{c}}$ are equal to 1.5. It is important to remark that when no traditional reinforcement is used ( $\rho s=0$ ), the FRC will be the sole responsible for providing the ductility. This is reflected in the result of Eq.(8) since f R3k becomes equal to fctk,fl. On the contrary, if the minimum amount of traditional reinforcement is used ( $\rho s=\rho s, \mathrm{~min}$ ), the result of Eq. (8) becomes 0 . This indicates that no contribution of the FRC for the ductility is required $(\mathrm{fR} 3 \mathrm{k}=0)$, hence no fibre reinforcement is needed.

It is evident that the use of Eq.(8) leads to a minimum strength criterion that the FRC must fulfil. This criterion is independent of the type of fibre (material, shape, anchor type, and other specific factors for each commercial fibre). Once the fibre type has been chosen, the $\mathrm{Cf}$ required must be evaluated through standardized tests that characterize the residual strength of FRC. Examples are the bending test on prismatic notched beams [21] or the Barcelona test [38] on cylindrical specimens, which has been reported in numerous scientific papers [39-40] and recently included in guidelines for the design of precast concrete segments [41]. 


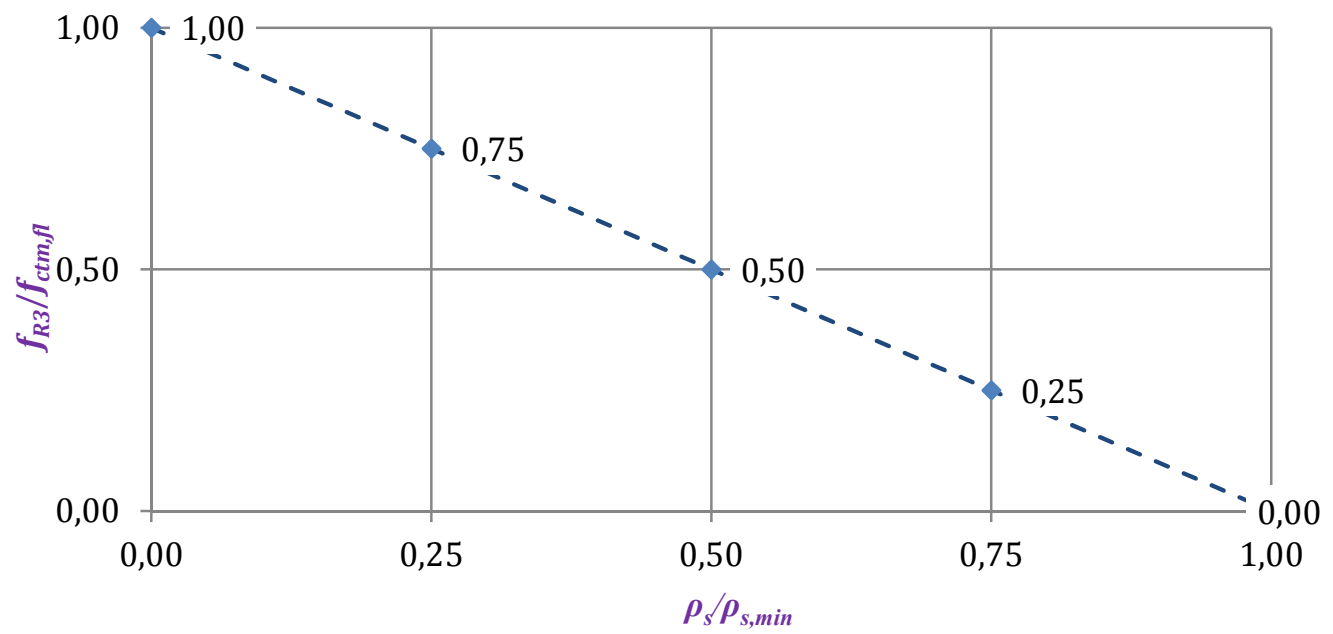

Figure 4. $\boldsymbol{f}_{\boldsymbol{R} 3, \boldsymbol{k}} / \boldsymbol{f}_{\boldsymbol{c t} \boldsymbol{k}, \boldsymbol{f} \boldsymbol{l}}$ ratio as a function of the $\boldsymbol{\rho}_{\mathbf{s}} / \boldsymbol{\rho}_{\mathrm{s}, \boldsymbol{m i n}}$ ratio obtained with Eq. 8. $\left(\boldsymbol{\gamma}_{\mathbf{c}}=\boldsymbol{\gamma}_{\mathbf{F R C}}=1.50\right)$.

\section{REDESIGN OF MONTACADA SHAFT SEGMENTS}

The construction of several vertical ventilation shafts is included in the project of the highspeed line that will connect Madrid, Barcelona and the border of France. One of the vertical shafts of this line is located in the municipality of Montcada i Reixac (Barcelona). The infrastructure has a depth of $59 \mathrm{~m}$ with an inner diameter of $9.20 \mathrm{~m}$ (Figure 5a) and is constructed with a vertical shaft machine (VSM, Figure $5 \mathrm{~b}$ ). The ground excavated consists of $4 \mathrm{~m}$ of landfill material close to the surface, followed by $16 \mathrm{~m}$ of sand and gravel strata, and 39 $\mathrm{m}$ of slate.

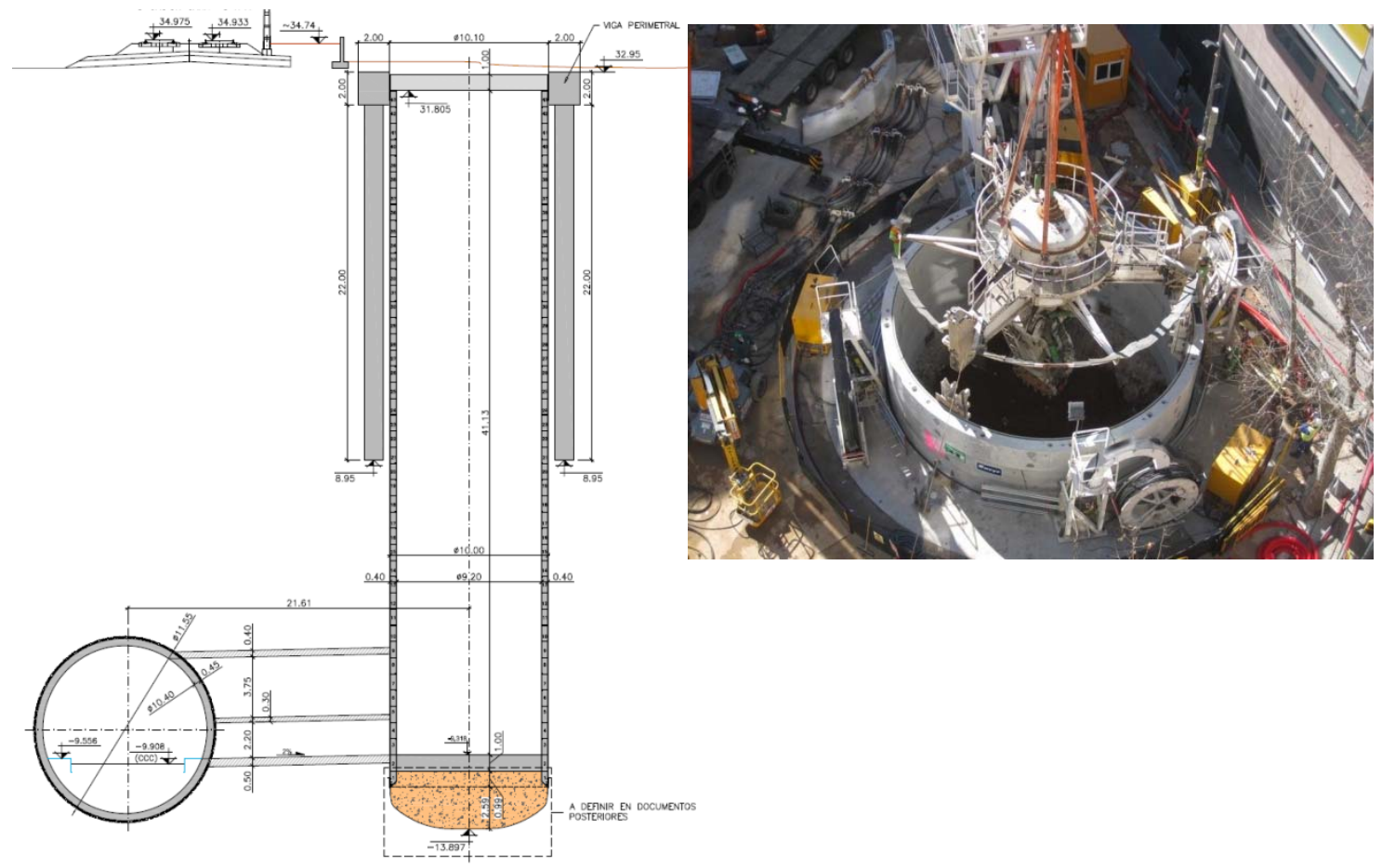

Figure 5. (a) Geometry of the Montcada shaft and (b) the VSM used for the shafts of the AVE Madrid French Border. 
According with the original project, the rings are formed by four segments (Figure 6) of C40tradicionally reinforced concrete $\left(f_{c k}=40 \mathrm{~N} / \mathrm{mm}^{2}\right)$ with a thickness of $0.40 \mathrm{~m}$, and a width of $1.0 \mathrm{~m}$. The main reinforcement is formed by two layers of $10 \Phi 16$ bars disposed along the width of the segment. Local and transversal reinforcements are also included in the original project. The concrete cover is $50 \mathrm{~mm}$ thick to ensure sufficient performance in the case of a fire and to comply with the requirements of EHE-08 [42].

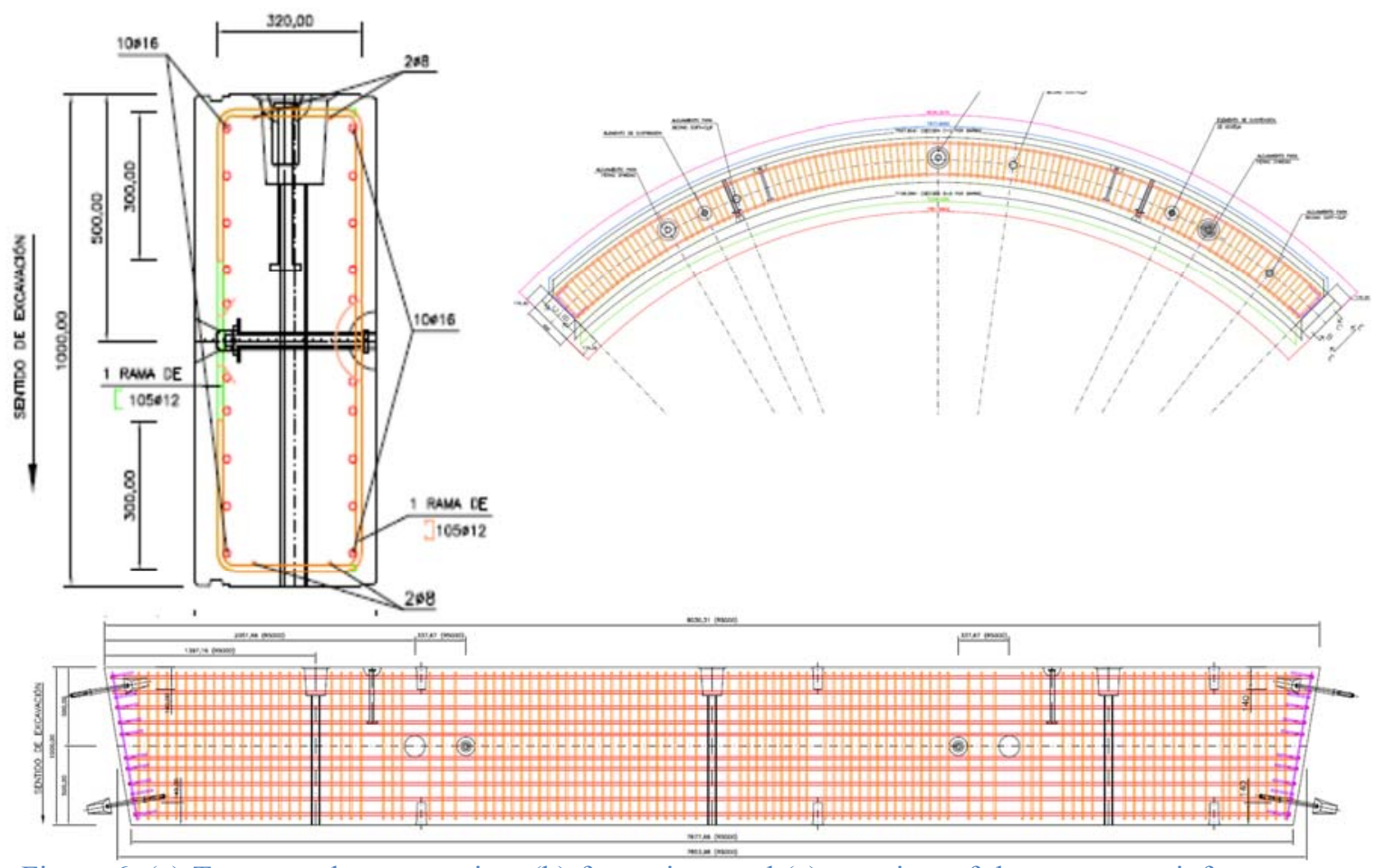

Figure 6. (a) Transversal cross-section, (b) front view, and (c) top view of the segment reinforcement originally proposed for the Montcada shaft.

The segments undergo different transient loading stages and support configurations during production: (1) demoulding (Figure 7a); (2) provisional storage after production (Figure 7b); (3) on-site storage (Figure 7c); and (4) lifting for its placement (Figure 7d). In the first two stages, the segment exhibits beam-type behaviour, whereas in the last two stages, the behaviour resembles that of a deep beam. For situations (1) and (2), the design requirement is that cracking does not occur considering a load safety factor $\gamma_{\mathrm{sw}}$ of 1.50 , which already takes into account the risk of impact or dynamic action.

The interaction with ground during the service phase was simulated with PLAXIS ${ }^{\circledR}$ software and with STATIK ${ }^{\circledR}$ software considering the geomechanical parameters presented in Table 2. The models were used to estimate the characteristic values of bending moment, normal force and shear force ( $\boldsymbol{M}_{k}, \boldsymbol{N}_{k}$, and $\boldsymbol{V}_{k}$, respectively) for sections at depths of 15,35 , and $59 \mathrm{~m}$. The characteristic values found are summarized in Table 2 along with the corresponding design values obtained with load safety factor of 1.50 . 


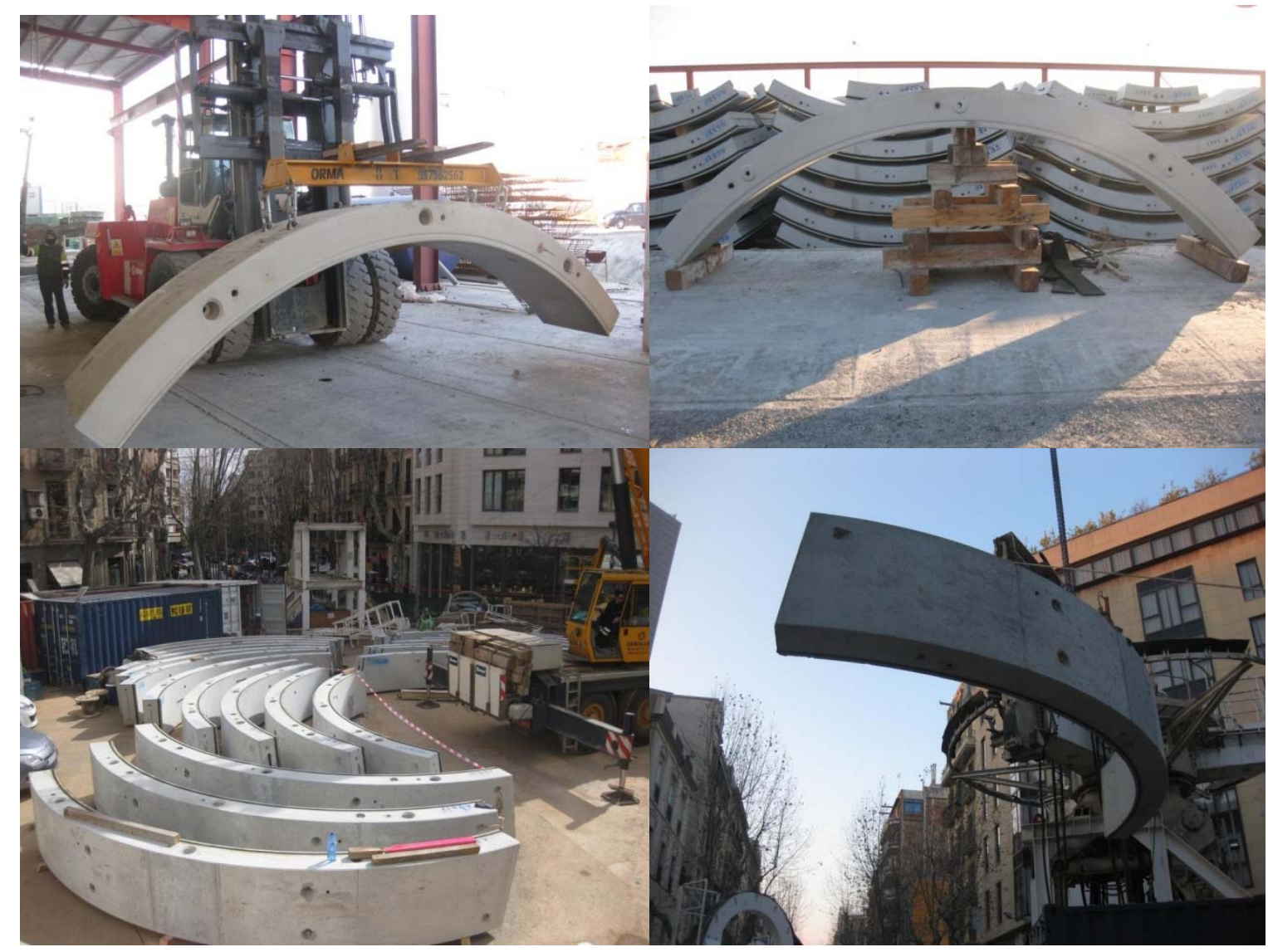

Figure 7. (a) Transport after mould release; (b) provisional support under storage; (c) support configuration in the work zone; and (d) lifting operation for the placement of the ring.

Table 2. Geomechanical parameters considered in the simulation

\begin{tabular}{|l|c|c|c|c|c|}
\hline Lithological & $\begin{array}{c}\boldsymbol{\gamma} \\
\left(\mathbf{k N} / \mathbf{m}^{3}\right)\end{array}$ & $\begin{array}{c}\mathbf{c} \\
\left(\mathbf{k N} / \mathbf{m}^{\mathbf{2}}\right)\end{array}$ & $\begin{array}{c}\mathbf{\Phi} \\
\left({ }^{\circ}\right)\end{array}$ & $\begin{array}{c}\mathbf{K}_{\mathbf{0}} \mathbf{n c}^{\mathbf{c}} \\
\mathbf{0}\end{array}$ & $\begin{array}{c}\mathbf{K}_{\mathbf{0}, \mathbf{x}} \\
\mathbf{0}\end{array}$ \\
\hline Landfill & 16.0 & 0 & 28 & 0.53 & 0.53 \\
\hline Sand & 21.0 & 10 & 35 & 0.50 & 0.50 \\
\hline Gravel sand & 21.0 & 0 & 38 & 0.50 & 0.50 \\
\hline Slate & 26.7 & 176 & 38 & 0.50 & 1.00 \\
\hline
\end{tabular}

For the transient load stages, it was verified that $\mathrm{M}_{\mathrm{d}}<\mathrm{M}_{\text {crd }}$ in the most unfavourable sections. Consequently, only minimum reinforcement is required. The goal of the investigation consists of completely removing the reinforcement, using an adequate amount of structural fibres to ensure the requirements established in MC 2010.

Applying Eq.(8) proposed in this article and considering $\rho$ s equal to 0 to account for the absence of traditional reinforcement, it is found that the FRC used should comply with a ratio $f_{R 3 k} / f_{c t k, f l}$ $\geq 1.0$. Furthermore, it must comply with $f_{R 1 k} / f_{L k}>0.4$ and $f_{R 3 k} / f_{R 1 k}>0.5$. Consequently, $f_{R 3 k} \geq$ $3.0 \mathrm{~N} / \mathrm{mm}^{2}$ and $1.2 \mathrm{~N} / \mathrm{mm}^{2}<\mathrm{f}_{\mathrm{R} 1 \mathrm{k}}<6.0 \mathrm{~N} / \mathrm{mm}^{2}$ (considering $\mathrm{f}_{\mathrm{Lk}}=\mathrm{f}_{\text {ctk } \mathrm{fl}}$ ) 
To verify if the FRC defined previously suffices the design requirement from Table 3 during service, an AES nonlinear analysis model of sections [43] was used. This model simulates the FRC mechanical behaviour with the constitutive equations proposed for this material in MC 2010. The AES model was used to evaluate the normal-bending moments $(\boldsymbol{N}-\boldsymbol{M})$ interaction diagram shown in Fig. 8. The design values from table 3 are also included in the same figure to evaluate if the performance of the cross-section complies with the ULS.

Figure 8. $\boldsymbol{N}-\boldsymbol{M}$ interaction diagram of the FRC segment.

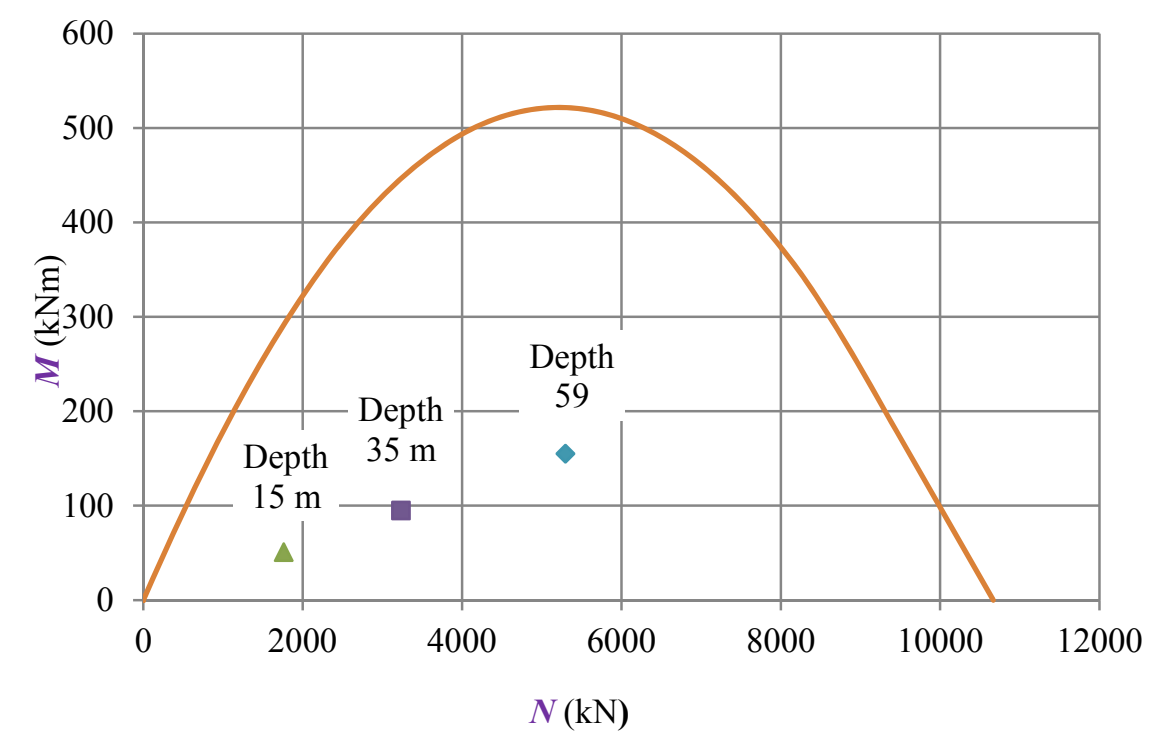

Table 3. Characteristic and design forces at different depths

\begin{tabular}{|c|c|c|c|c|c|c|}
\hline Level & $\begin{array}{c}\boldsymbol{M}_{\boldsymbol{k}} \\
(\mathrm{mkN})\end{array}$ & $\begin{array}{c}\boldsymbol{M}_{\boldsymbol{d}} \\
(\mathrm{mkN})\end{array}$ & $\begin{array}{c}\boldsymbol{V}_{\boldsymbol{k}} \\
(\mathrm{kN})\end{array}$ & $\begin{array}{c}\boldsymbol{V}_{\boldsymbol{d}} \\
(\mathrm{kN})\end{array}$ & $\begin{array}{c}\boldsymbol{N}_{\boldsymbol{k}} \\
(\mathrm{kN})\end{array}$ & $\begin{array}{c}\boldsymbol{N}_{\boldsymbol{d}} \\
(\mathrm{kN})\end{array}$ \\
\hline$-15 \mathrm{~m}$ & 34 & 51 & 53 & 79 & 1174 & 1763 \\
\hline$-35 \mathrm{~m}$ & 63 & 95 & 97 & 145 & 2157 & 3235 \\
\hline$-59 \mathrm{~m}$ & 103 & 155 & 159 & 238 & 3532 & 5298 \\
\hline
\end{tabular}

Notice that all points are within the $\mathrm{N}-\mathrm{M}$ envelope. The results indicate that the cross-section operates under flexo-compression with dominant compressions. Consequently, the section does not crack when subjected to the design stresses and the FRC proposed is adequate for service phases. Therefore, it is possible to substitute the entire main tensile reinforcement by fibres

\section{EXPERIMENTAL PROGRAMME TO ACCESS $\mathrm{C}_{\mathrm{f}}$}

Once the mechanical requirements for FRC are set by considering the different load stages, the value of $\boldsymbol{C}_{f}$ needed to satisfy them must be assessed. An optimisation experimental programme is proposed with this aim, considering two types of con- cretes: one conventional (CSFRC) and one self-compacting (SCSFRC). For each concrete type, three $\mathrm{C}_{\mathrm{f}}$ values $(30,45$, and $60 \mathrm{~kg} / \mathrm{m} 3)$ 
were used to estimate the minimum needed to comply with the performance parameters obtained in Section 4 (Cf,min).

In total, six concrete mixes were produced with the compositions presented in Table 4. A steel fibre with hook-shaped anchorage was used. These fibres had a minimum elastic limit of 1000 $\mathrm{N} / \mathrm{mm} 2$, length of $50 \mathrm{~mm} \pm 1 \mathrm{~mm}$ and diameter of $1.0 \mathrm{~mm} \pm 0.1 \mathrm{~mm}$.

In the fresh state, the consistency was characterized with the slump flow test [44] for the CSFRC and with the flow extent test [45] for the SCSFRC. Moreover, the content of occluded air and the density were measured using the tests described in [46] and in [47], respectively.

Table 4. Composition of FRCC and FRSCC [in $\mathrm{kg} / \mathrm{m} 3]$

\begin{tabular}{|l|c|c|}
\hline Mixtures & CFRC & FRSCC \\
\hline Sand 0/5 & 817 & 1200 \\
\hline Fine aggregate 5/15 & 404 & 500 \\
\hline Coarse aggregate 12/20 & 810 & 200 \\
\hline Water & 156 & 165 \\
\hline CEM I 52.5 R & 312 & 380 \\
\hline Superplasticizer & 2.19 & 4.56 \\
\hline
\end{tabular}

The results of the fresh state tests are presented in Table 5. The SCSFRC reached flow extents above the $60 \mathrm{~cm}$ established in the [46] as a minimum for self-compacting concrete. It was also observed that the CSFRC present an occluded air content approximately 2.5 smaller than the SCSFRC. This may be the consequence of the higher amount and different type of superplasticizer, as well as, the higher mortar content used in the former to increase the flowability.

Table 5. Test results on fresh state.

\begin{tabular}{|l|c|c|c|c|}
\hline Series & $\begin{array}{c}\text { Cone test } \\
(\mathbf{c m})\end{array}$ & $\begin{array}{c}\text { Flow test } \\
(\mathbf{c m})\end{array}$ & $\begin{array}{c}\text { Air content } \\
\mathbf{( \% )}\end{array}$ & $\begin{array}{c}\text { Density } \\
\mathbf{( k g / \mathbf { m } ^ { 3 }}\end{array}$ \\
\hline FRCC-30 & 3 & - & 1.8 & 2481 \\
\hline FRCC-45 & 5 & - & 2.1 & 2481 \\
\hline FRCC-60 & 3 & - & 2.2 & 2494 \\
\hline FRSCC-30 & - & 65 & 5.4 & 2394 \\
\hline FRSCC-45 & - & 65 & 5.5 & 2394 \\
\hline FRSCC-60 & - & 67 & 7.4 & 2319 \\
\hline
\end{tabular}

To characterize the mechanical behaviour of each mixture in the hardened state, nine cylindrical specimens were moulded $(\Phi 150 \times 150$ in $\mathrm{mm})$ to evaluate the compressive strength $\mathrm{f}_{\mathrm{C}}$ according with [48] at 1, 7, and 28 days of age. In addition to that, three prisms $(150 \times 150 \times$ $600 \mathrm{in} \mathrm{mm}$ ) were cast to perform the notched three-point test [28] and evaluate fL and fRi at 28 
days. Non-destructive inductive tests were also performed to evaluate the $\mathrm{C} f$ values following [49-50], as shown in Fig. 9a. This test was conducted on cubic specimens (150 mm of side) cut from the already tested prismatic specimens. These specimens were extracted respecting the distances indicated in Fig. $9 \mathrm{~b}$ to avoid the influence of the wall effect and of the cracked section. Notice that two cubic specimens were symmetrically extracted from each beam subjected to the bending test.
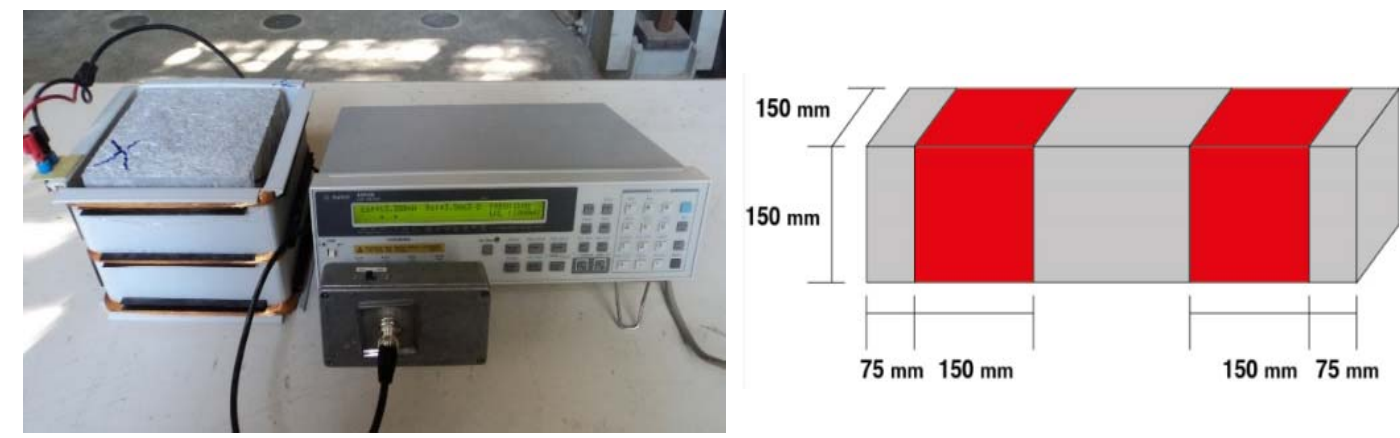

Fig. 9. (a) Inductive test and (b) cubic specimens cut from the tested prisms

Table 6 presents the values of $\mathrm{Cf}$ for each cubic specimen, the mean values of $\mathrm{Cf}(\mathrm{Cfm})$, and the coefficient of variation of the results (CV). Table 7 shows the evolution of compressive strength and the strengths measured in the bending tests. Fig. 10 presents the average F-CMOD curves obtained in the bending test for the concrete mixes tested.

Table 6. Average values of $\boldsymbol{f}_{\boldsymbol{c}}, \boldsymbol{f}_{\boldsymbol{L}}, \boldsymbol{f}_{\boldsymbol{R} 1}$, and $\boldsymbol{f}_{\boldsymbol{R}}\left(\mathrm{N} / \mathrm{mm}^{2}\right)$ and $\mathrm{CV}(\%)$

\begin{tabular}{|l|l|l|l|c|c|c|}
\hline \multirow{2}{*}{ Series } & \multicolumn{3}{|c|}{$\mathbf{f}_{\mathrm{cm}} / \mathbf{C V}$} & $\mathbf{f}_{\mathrm{Lm}} / \mathbf{C V}$ & $\mathbf{f}_{\mathbf{R} 1 \mathrm{~m} / \mathbf{C V}}$ & $\mathbf{f}_{\mathrm{R} 3 \mathrm{~m}} / \mathbf{C V}$ \\
\cline { 2 - 7 } & $\mathbf{1}$ days & $\mathbf{7 ~ d a y s}$ & $\mathbf{2 8}$ days & \multicolumn{3}{c|}{$\mathbf{2 8}$ days } \\
\hline FRCC-30 & $20.2 / 1.2$ & $54.4 / 1.8$ & $65.1 / 0.3$ & $5.2 / 1.1$ & $3.2 / 8.4$ & $2.4 / 1.8$ \\
\hline FRCC-45 & $19.7 / 2.4$ & $54.6 / 0.8$ & $63.9 / 1.5$ & $5.8 / 3.8$ & $5.1 / 20.3$ & $3.9 / 22.2$ \\
\hline FRCC-60 & $21.5 / 1.5$ & $54.8 / 0.2$ & $64.9 / 1.9$ & $5.5 / 12.4$ & $4.8 / 19.3$ & $4.3 / 22.1$ \\
\hline FRSCC-30 & $25.4 / 2.1$ & $56.1 / 2.9$ & $70.5 / 1.2$ & $5.0 / 9.9$ & $2.9 / 28.4$ & $2.6 / 32.7$ \\
\hline FRSCC-45 & $18.3 / 0.8$ & $55.2 / 1.8$ & $66.3 / 1.3$ & $5.8 / 8.5$ & $4.7 / 1.9$ & $4.8 / 5.84$ \\
\hline FRSCC-60 & $17.1 / 1.5$ & $53.4 / 1.3$ & $66.7 / 4.2$ & $5.9 / 2.7$ & $7.1 / 17.2$ & $7.1 / 11.6$ \\
\hline
\end{tabular}

Table 7. Values of $\boldsymbol{C}_{f}$ and $\boldsymbol{C}_{f \boldsymbol{m}}$ in $\mathrm{kg} / \mathrm{m}^{3}$ and CV (\%) obtained with the inductive test.

\begin{tabular}{|c|c|c|c|c|c|c|c|c|}
\hline \multirow{3}{*}{ Series } & \multicolumn{6}{|c|}{$C_{f}\left(\mathrm{~kg} / \mathrm{m}^{3}\right)$} & \multirow{3}{*}{$C_{f m}$} & \multirow{3}{*}{ CV } \\
\hline & \multicolumn{2}{|c|}{ Specimen 1} & \multicolumn{2}{|c|}{ Specimen 2} & \multicolumn{2}{|c|}{ Specimen 3} & & \\
\hline & $1-1$ & $1-2$ & $2-1$ & $2-2$ & 3-1 & $3-2$ & & \\
\hline FRCC-30 & 31.5 & 30.1 & 34.9 & 28.4 & 33.1 & 31.5 & 31.6 & $6.6 \%$ \\
\hline FRCC-45 & 54.3 & 43.4 & 41.9 & 41.4 & 51.5 & 39.8 & 45.4 & $12.1 \%$ \\
\hline FRCC-60 & 65.3 & 67.2 & 57.2 & 64.3 & 56.3 & 55.7 & 61.0 & $7.7 \%$ \\
\hline FRSCC-30 & 24.4 & 25.8 & 30.6 & 25.6 & 28.5 & 33.0 & 28.0 & $10.9 \%$ \\
\hline FRSCC-45 & 39.4 & 37.6 & 48.2 & 50.7 & 49.8 & 49.0 & 45.8 & $11.4 \%$ \\
\hline FRSCC-60 & 59.4 & 63.0 & 47.2 & 54.3 & 69.0 & 71.4 & 60.7 & $13.7 \%$ \\
\hline
\end{tabular}




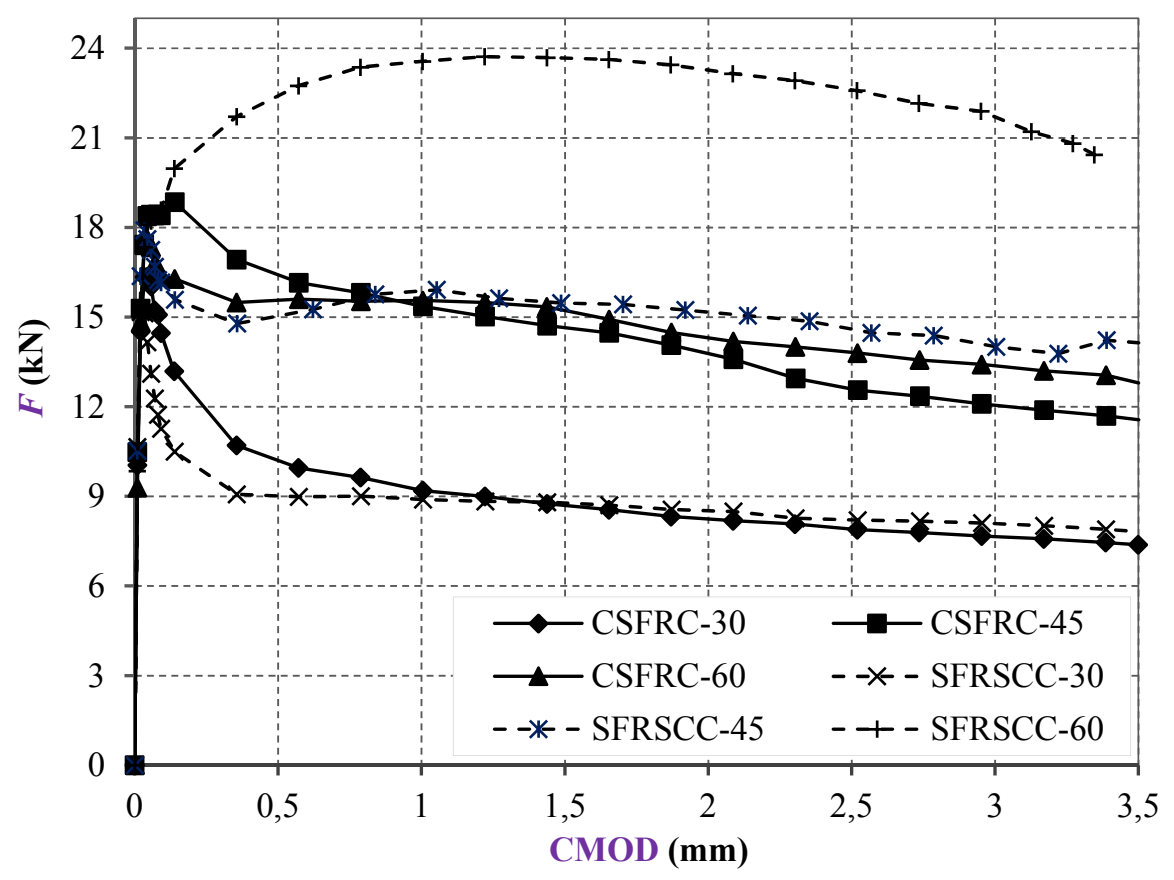

Fig. 10. Average $\boldsymbol{F}$ - CMOD curves obtained from three-point bending tests.

Regarding the results presented in Tables 6 and 7 and in Figure 10, the following can be concluded:

- The average fibre content measured with the inductive method approximates the nominal content of each mix. The coefficient of variation among samples is higher in the case of SCSFRC than in the CSFRC. This is probably the result of the bigger freedom of movement of the fibres in the mixture of SCSFRC, which makes fibre distribution and content more sensible to variations in the casting procedure.

- In the short term, the values of $f_{c}$ are bigger than the minimum $15 \mathrm{~N} / \mathrm{mm}^{2}$ established in the project for demoulding the segments. At 28 days of age, the values of $f_{\mathrm{cm}}$ seem independent of the value of $\mathrm{C} f$, being around 5\% higher for the SCSFRC than for the CSFRC. This slight difference may be attributed to the higher cement content in the for- mer (Table 4). The minimum fcm at 28 days is $63.9 \mathrm{~N} / \mathrm{mm}^{2}$. Hence, the different concrete dosages presented a concrete strength class above the $\mathrm{C} 40$ established in the project. It is important to remark that this is a common situation found in tunnels since the limiting strength is observed at early age for the demoulding, not at 28 day.

- The coefficient of variation of the results of the bending test is especially high for the CSFRC mixes and for SCSFRC with $30 \mathrm{~kg} / \mathrm{m}^{3}$. Values of ap- proximately $25 \%$ are expected for this type of material [51], these being motivated by errors inherent to the test itself as well as the randomness in the distribution and orientation of the fibres [52].

- The residual responses measured in the bending test for CSFRC and for SCSFRC are similar, except in the mixes with $60 \mathrm{~kg} / \mathrm{m}^{3}$ of fibres. In this particular case, the mix with 
self-compacting concrete presents hardening, whereas the mix with conventional concrete presents soft- ening with a behaviour close to that of CSFRC-40. This may be partially attributed to the high scatter in the residual strength of mixes CSFRC- 40 and SCSFRC-60.

Following the same approach described in [53-54], the relationships fRk1-Cf and fRk3-fRk1 depicted in Fig. 11 are obtained. It must be highlighted that the procedure proposed in RILEM TC 164-TDF [55] was used to derive the characteristic values of fRi.
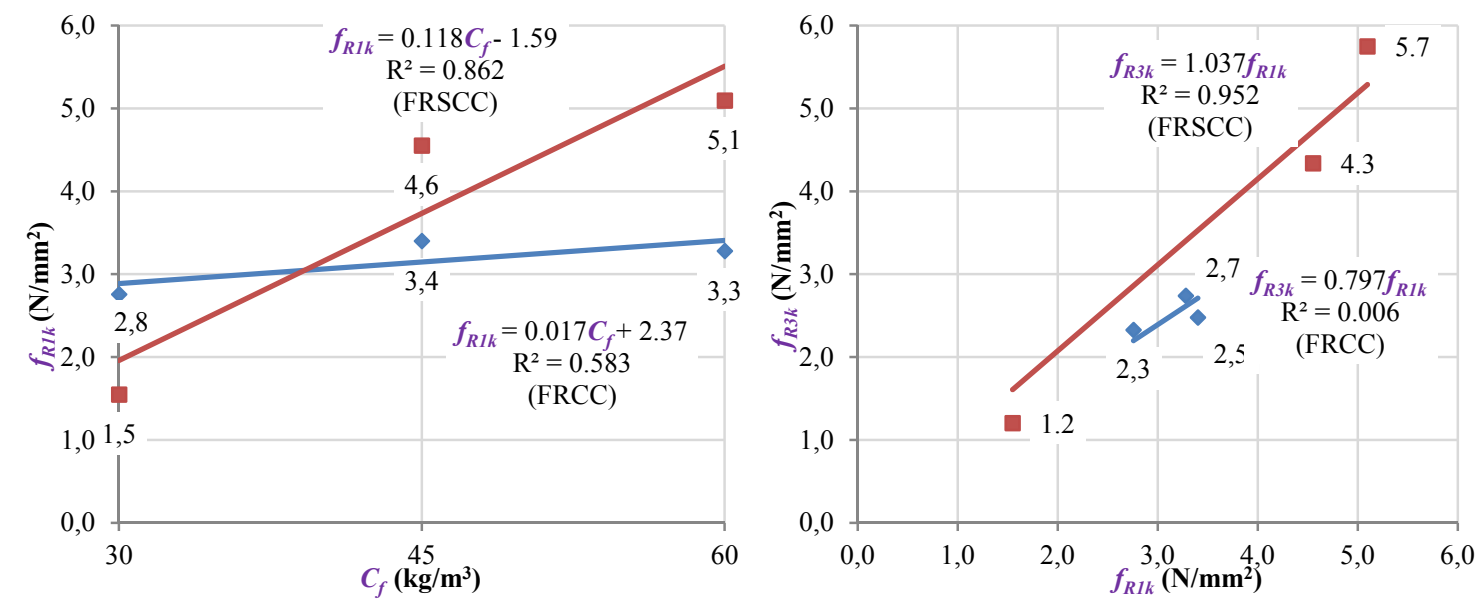

Fig. 10. $\boldsymbol{f}_{\boldsymbol{R} 1 \boldsymbol{k}}-\boldsymbol{C}_{\boldsymbol{f}}$ relationship (a) and $\boldsymbol{f}_{\boldsymbol{R} 3 \boldsymbol{k}}-\boldsymbol{f}_{\boldsymbol{R} 1 \boldsymbol{k}}$ relationship (b) obtained with the tensile strength tests, EN 14651

Figure 11 reveals that the $f_{R k 1}-C_{f}$ and $f_{R k 3}-f_{R k 1}$, relationships fit a linear tendency with $\mathrm{R}^{2}$ bigger than 0.850 ) for SCSFRS. For CSFR, the $\mathbf{R}^{2}$ values are unacceptable due to the high scatter obtained in the results of residual strength. Therefore, the linear regression obtained for SCSFRC will be used to evaluate $\mathrm{C} f$,min. Introducing in this equation the requirements derived in Section 4 gives a $\mathrm{C}$, min of $38 \mathrm{~kg} / \mathrm{m}^{3}$.

However, it is important to consider that the specimens used in the bending test would lead to a flexural response higher than that expected in the real-size segment due to the scale effect associated with the height of the cross section. It is estimated that to achieve a $f_{c t k}$,fl of 3.0 $\mathrm{N} / \mathrm{mm}^{2}$ in the real segment, a fctk,fl of around $4.0 \mathrm{~N} / \mathrm{mm}^{2}$ would be needed in the small-scale bending test. Hence, it was finally established that a fR3k bigger than $4.0 \mathrm{~N} / \mathrm{mm}^{2}$ at 28 days is required. Using this value in the linear regression from Fig. 11 gives a $\mathrm{Cf}$,min of $48.6 \mathrm{~kg} / \mathrm{m}^{3}$. There fore, for industrial reasons, a fibre content equal to $50 \mathrm{~kg} / \mathrm{m}^{3}$ was fixed regardless of the concrete type.

Notice that these segments were produced to be tested up to failure under controlled conditions at concrete age t $\mathrm{N} 28$ days. Therefore, the minimum strength requirements were established for $\mathrm{t}=28$ days. In this sense, in a large standardized production, the design procedure presented in Section 3 should be applied to the different load transient stages (Fig. 7) to derive the 
ratios $\mathrm{fR} 3 \mathrm{k}\left(\mathrm{t}^{*}\right) / \mathrm{fLOPk}\left(\mathrm{t}^{*}\right)$ at a given time. Posteriorly, the suitability of the material can be assessed obtaining the fR3k-t curves from the 3-point bending test on notched beams as proposed in [56].

\section{FULL SCALE TEST}

A conventional fibre-reinforced concrete segment (CSFRPC) and self-compacting fibrereinforced concrete (SCSFRPS) with $\boldsymbol{b}=1200 \mathrm{~mm}$ and $h=350 \mathrm{~mm}$, were produced for a fullscale test intended to verify if the elements comply with the ductility require- ments established. The compositions of the concrete presented in Table 4 with a fibre content of $50 \mathrm{~kg} / \mathrm{m}^{3}$ was used to cast the segments. No additional reinforcement was included.

The concrete was poured with a skipper (Fig. 12a). The segment with conventional concrete was vibrated with internal and external vibrators. Both segments were cast on the same day and were unmoulded after $16 \mathrm{~h}$ of casting (Fig. 12b). The segments were then placed over the support shown Fig. 12c for their storage and transport. No surface cracks were detected in any of the visual inspections performed.

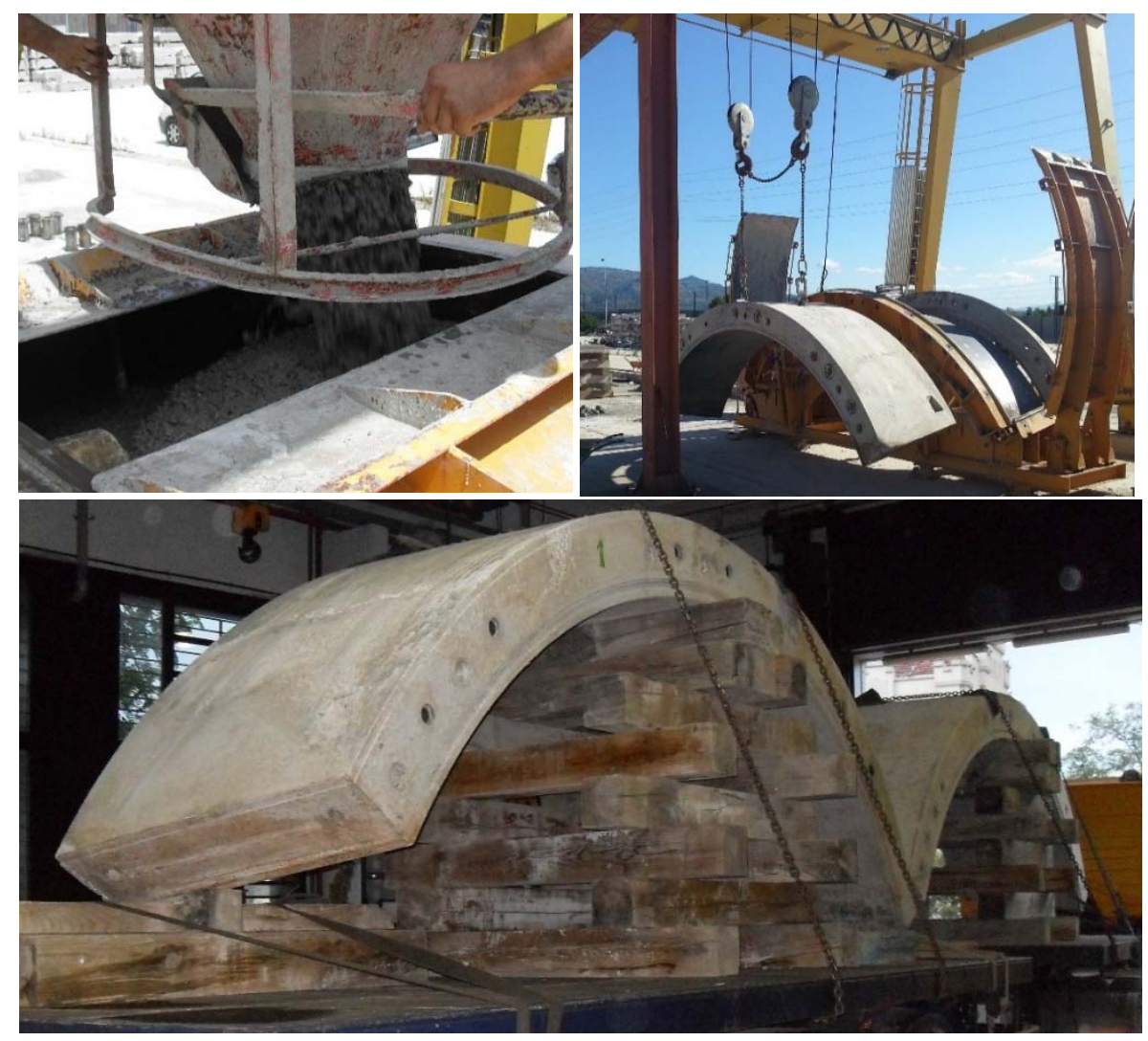

Fig. 12. (a), Concrete pouring (b), demoulding operation and (c) transport of the segments.

The segments were subjected to bending tests at 90 (CSFRPS) and 100 (SCSFRPS) days of age. The setup used is shown in Fig. 13a. It simulates a concentrated load pattern that might occur during transient stages or due to non-symmetric loading in service, both of which tend to be critical in terms of the design of the segment. 


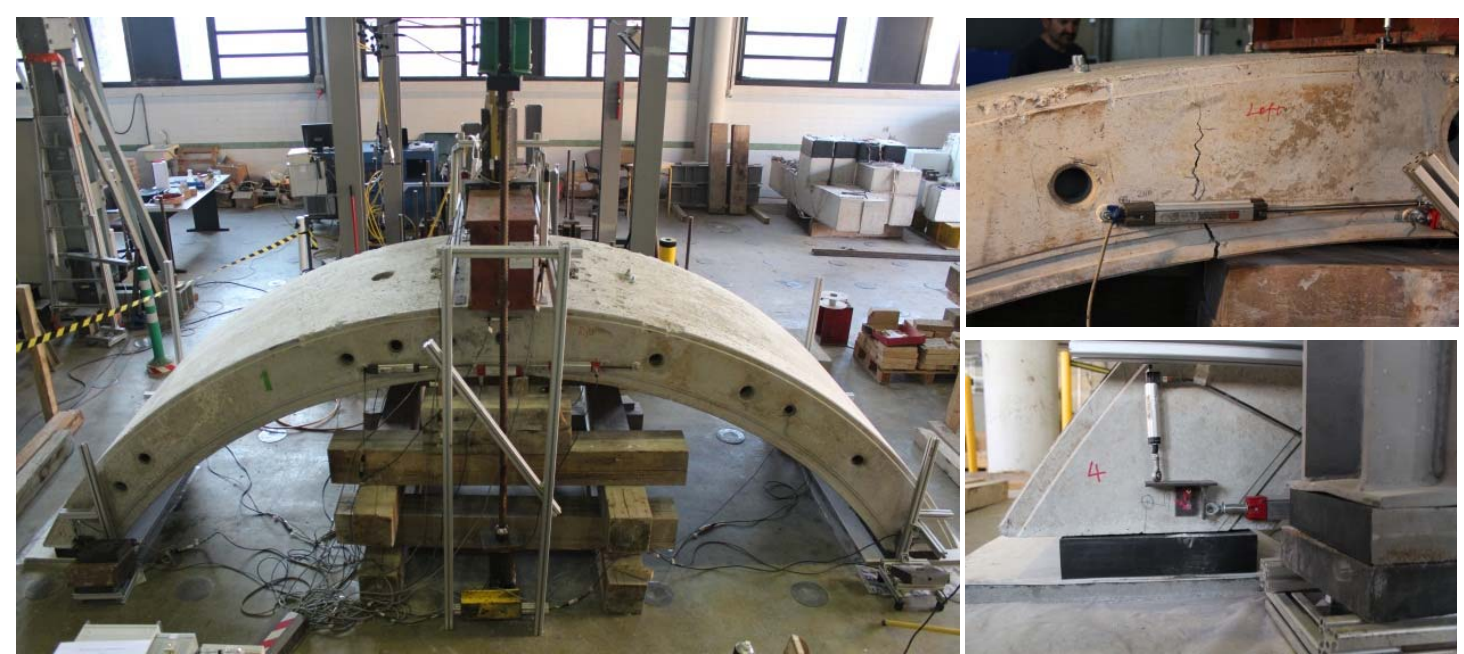

Fig. 13. (a), Segment support configuration; LVDT to measure (b) the the left face (c), roght face width of the cracks due to bending.

The segments were supported at the both ends. Prior to the test, the extremities of the segment had been cut to achieve a flat surface parallel to the reaction slab. The free-span (1) measured horizontally as a result of the cut was $5500 \mathrm{~mm}$. Different materials were placed between the segment and the reaction slab in order to homogenize the contact and to reduce the friction. First, a 40-mm cement self-levelling mortar M20 was cast and left to cure over the reaction slab to regularize the surface. Over this layer, a 2-mm plastic sheet and a 2-mm Teflon sheet were placed. Finally, a neoprene layer with dimensions of $300 \times 200 \times 63 \mathrm{~mm}$ was allocated along the width of the segment.

The load was applied with a hydraulic piston at mid-span. The piston introduced a constant displacement rate of $0.9 \mathrm{~mm} / \mathrm{min}$ towards the reaction slab. A thick steel beam and a neoprene sheet were placed between the piston and the segment to guarantee a uniform distribu- tion of the load along the width of the segment. Displacement sensors were installed in the supports to measure the vertical and horizontal movements throughout the test. Furthermore, six LVDT were placed (three in each face of the central segment) to measure the width of the cracks near the loading zone, as shown in Fig. $13 \mathrm{~b}$ and c.

The results in terms of load (F) and crack width (w) are presented in Fig. 14a. The w depicted is the average value of crack width measured in both sides. A linear elastic behaviour is observed until reaching the cracking load $(\mathrm{Fcr})$ of $61.5 \mathrm{kN}$ and $68.0 \mathrm{kN}$ for the CSFRPS and SCSFRPS, respectively. Since the geometry is equivalent in both tests, the $9.5 \%$ difference in the values of $F_{c r}$ may be attributed to differences in the fL of each type of concrete.

In both types of segment, a single main crack was formed (Fig. 12b). After that, a softening behaviour with a ductile response was observed 


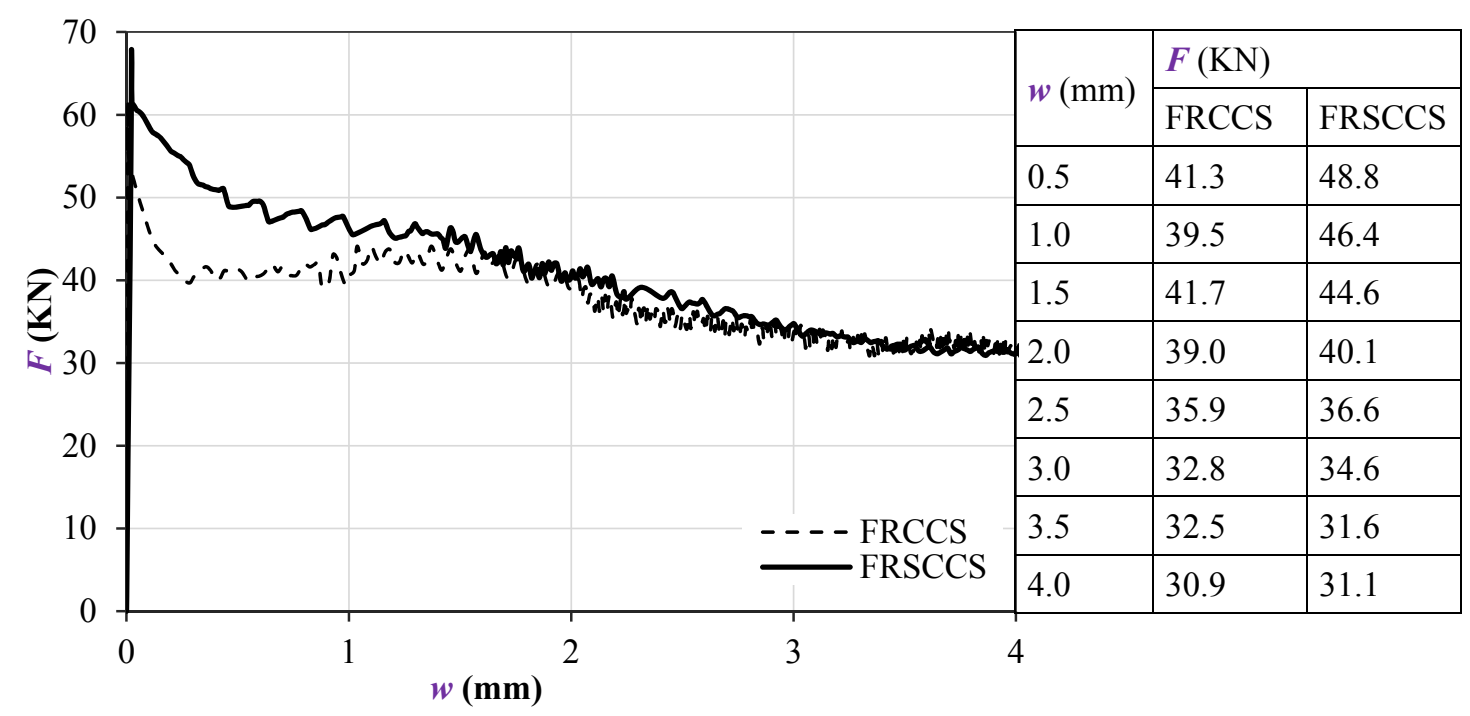

Fig. 14. a) Load (F) - crack width (w) curves and b) detail values obtained in the full-scale tests.

The results presented in Figure $14 \mathrm{~b}$ also show that up to values of w close to $1.5 \mathrm{~mm}$, the SCSFRPS presents a load that is, at most, $18.3 \%$ higher compared with that of CSFRPS. For w bigger than $1.5 \mathrm{~mm}$, the response of both segments was equivalent in terms of $\mathrm{F}$, thus confirming the general trend observed in the small scale experimental programme from Section 5.

After the test, the number of fibres present in the cracked section of each segment was counted (Fig. 15). In total 1026 fibres were found for the CSFRPS and 1082 fibres were found for the SCSFRPS. This slight difference (only 5\%) in the number of fibres justifies the equivalent mechanical behaviour obtained after cracking. It reflects that the influence of the rheology of concrete and the casting procedure on the fibre distribution was small, justifying the similar results obtained for conventional and self-compacting FRC.

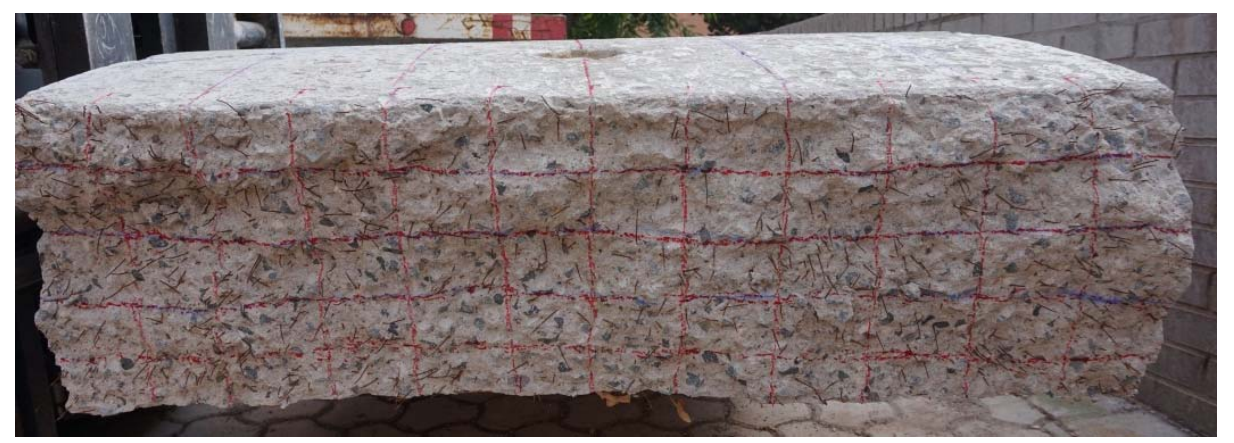

Fig. 15. Grid generated to count the fibres in the fracture sections of the segments.

At the design level and based on the discussions from Sections 3 and 4, it is evident that both segments present ductile behaviour since large displacements are observed after reaching Fcr (mean value of $64.8 \mathrm{kN}$ for the two segments) with a gradual softening response. Furthermore, considering the ultimate load $(\mathrm{Fu})$ as that associated with a value of $\mathrm{w}=2.5 \mathrm{~mm}$ (in line with 
the value of fR3 accepted in MC 2010 for the design in ULS), the results of Fig. 14b indicate that $\mathrm{Fu}$ reaches values of $35.9 \mathrm{kN}$ for the CSFRPS and $36.6 \mathrm{kN}$ for the SCSFRPS, with a mean value of $36.3 \mathrm{kN}$.

In this regard, the design performed in Section 4 is valid because Eq. (8) is presented with characteristic strength values, whereas the tests results must be evaluated with mean values. Thus, the $f_{c t k}$,fl of $4.0 \mathrm{~N} / \mathrm{mm}^{2}$ considered for the C60 leads to Mcrk $=98 \mathrm{kNm}$. The bending moment associated with the self-weight is $\mathrm{Mpp}=\mathrm{q} \cdot 12 / 8=45 \mathrm{kNm}(\mathrm{q}=10.5 \mathrm{kN} / \mathrm{m})$ The moment associated with force $\mathrm{F}^{*}$ that would generate cracking under the design conditions is $\mathrm{MF}^{*}, \mathrm{cr}=\mathrm{Mcrk}-\mathrm{Mpp}=53 \mathrm{kNm}$. Therefore, the cracking load under the setup configuration used could be calculated as $\mathrm{F}^{*} \mathrm{cr}=4 \mathrm{MF}^{*}, \mathrm{cr} / \mathrm{l}=38.5 \mathrm{kN}$ and should be compared with $\mathrm{Fu}=$ $36.3 \mathrm{kNm}$ to be consistent with the proposed design strategy and to evaluate the suitability of Eq. (8)

It is observed that $\mathrm{F}^{*} \mathrm{cr}$ is $5.7 \%$ bigger than $\mathrm{Fu}$. Therefore, the presented design would be slightly on the unsafe side. However, it is important to remark that the $\mathrm{fct}_{\mathrm{ct}} \mathrm{fl}$ estimated from these full-scale tests is $5.1 \mathrm{~N} / \mathrm{mm} 2$, which is $27.5 \%$ bigger than the $4.0 \mathrm{~N} / \mathrm{mm} 2$ considered in the design for $\mathrm{C} 60$ concrete. Consequently, given the increment of $\mathrm{fct}, \mathrm{fl}$, the cracking risk is lower as well as the likelihood of reaching an ULS.

Considering the hypotheses and design criterion presented in Section 3 and the experimental campaign performed on the material and the segments, it was decided to modify the project reinforcement presented in Fig. 11. In the new design, part of the segments were rein forced solely with $50 \mathrm{~kg} / \mathrm{m} 3$ of the structural steel fibres

\section{CONCLUSIONS}

This study addressed the design and the characterization of fibre- reinforced concrete segments to be used in the vertical shafts constructed with VSM. This type of structural element primarily works under compression during the service phase and the only tensile stresses that appear in the segments are produced during the transitional phases and have a low cracking risk. Therefore, the main bending reinforce- ment usually responds to minimum quantities of

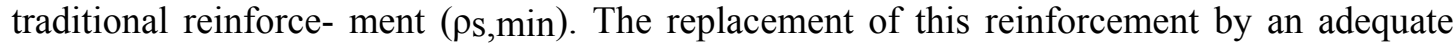
quantity of structural fibres $(\mathrm{C} f)$ is a possibility that may bring technical as well as economic advantages. The following conclusions are derived from this study.

- The fR3/fL ratio is linearly related with the $\rho_{\mathrm{S}} / \rho_{\mathrm{s}}, \mathrm{min}$ ratio, which also takes into account the partial safety coefficients $\gamma_{\mathrm{c}}$ and $\gamma_{\mathrm{FRC}}$ through the analytical equation (Eq. (8)) proposed here. This equation helps to establish the minimum FRC requirements for hybrid sections (fibres + bars) subjected to reduced stresses (lower than the cracking moment $\mathrm{M}$ cr). This expression represents an important contribution for the design of 
FRC elements and has been proposed in the docu- ment by fib committee 1.4.1. "Tunnels in fibre reinforced concrete".

- Based on the experimental campaign and the application of Eq.(8) for the redesign of the segment from the Montcada shaft (Barcelona), it was observed that the value of $\mathrm{Cf}$ that allowed the complete replace- ment of the reinforcement proposed in the initial project (minimum by mechanic criteria) is $50 \mathrm{~kg} / \mathrm{m} 3$.

- The mechanical behaviours of the CSFRPS and the SCSFRPS cast with $50 \mathrm{~kg} / \mathrm{m} 3$ of fibres in the full-scale bending tests were both ductile. Furthermore, an almost equivalent response was obtained in both segments for cracking when $\mathrm{w} \geq 1.5 \mathrm{~mm}$, which shows the reduced influence of rheology in fresh-state concrete on the behaviour in ULS. In this regard, the number of fibres in the failure sections differs by less than $5 \%$ for each segment, thus justifying the similar results.

\section{Acknowledgements}

The authors would like to thank the Ministry of Science and Innovation for the economic support received through Research Project BIA2010-17478: Construction processes by means of fibre reinforced concretes and BIA2013-49106-C2-1-R. The first author would like to acknowledge the scholarship received from the China Scholarship Council and the support from the Taiyuan University of Technology.

\section{References}

[1] fib Bulletins 65-66, Model Code 2010 Final Draft, fédération internationale du béton (fib), Lausanne, Switzerland, 2010.

[2] A. Caratelli, A. Meda, Z. Rinaldi, P. Romualdi, Structural behaviour of precast tunnel segments in fibre reinforced concrete, Tunn. Undergr. Space Technol. 26 (2) (2011) 284291.

[3] J. Poh, K.H. Tan, G.L. Peterson, D. Wenm, Structural Testing of Steel Fibre Reinforced Concrete (SFRC) Tunnel Lining Segments in Singapore, WTC, Budapest, Hungary, 2009.

[4] G.P. Lee, G.J. Bae, D.Y. Moon, T.S. Kang, S.H. Chang, Evaluation of steel fibre reinforcement effect in segment lining by full scale bending test, J. Korean Tunn. Undergr. Sp Assoc. 15 (3) (2013) 215-223.

[5] R. Gettu, B. Barragán, T. García, G. Ramos, C. Fernández, R. Oliver, Steel fibre reinforced concrete for the Barcelona metro line 9 tunnel lining, The 6th RILEM Symposium on FRC, Varenna, Italy 2004, pp. 141-156 (September 20-22). 
[6] J. Beno, M. Hilar, Steel fibre reinforced concrete for tunnel lining — verification by extensive laboratory testing and numerical modelling, Acta Polytechnia 53 (4) (2013) 329-337 (Czech Technical University, Prague).

[7] H. Mashimoto, N. Isago, T. Kitani, Numerical approach design of tunnel concrete lining considering effect of fibre reinforcements, Tunnelling and Underground Space Technology. Underground Space for Sustainable Urban Development. Proceedings of the 30th ITA-AITES WTC 2004, 2004 (22-27 May, Singapore).

[8] S. Abbas, A. Soliman, M. Nehdi, Structural behaviour of ultra-high performance fibre reinforced concrete tunnel lining segments, FRC 2014 Joint ACI-fib International Workshop. Fibre Reinforced Concrete Applications, 2014 (24-25 July, Montreal, Canada).

[9] M. Blazejowsky, Flexural Behaviour of Steel Fibre Reinforced Concrete Tunnel Linings(Electronic Thesis and Dissertation Repository) University of Western Ontario, Canada, 2012.

[10] G.A. Plizzari, G. Tiberti, Steel fibres as reinforcement for precast tunnel segments, Tunn. Undergr. Sp. Technol. 21 (3-4) (2006) 438-439.

[11] M. di Prisco, G. Plizzari, L. Vandewalle, Fibre reinforced concrete: new design perspectives, Mater. Struct. 42 (9) (2009) 1261-1281.

[12] J. Walraven, High performance fibre reinforced concrete: progress in knowledge and design codes, Mater. Struct. 42 (9) (2009) 1247-1260.

[13] A. de la Fuente, A. Blanco, P. Pujadas, A. Aguado, Experiences in Barcelona with the use of fibres in segmental linings, Tunn. Undergr. Space Technol. 27 (1) (2011) 60-71.

[14] W. Angerer, M. Chappell, Design of steel fibre reinforced segmental lining for the gold coast desalination tunnels, 13th Australian Tunneling Conference 2008,

[15] C. Molins, O. Arnau, Experimental and analytical study of the structural response of segmental tunnel linings based on an in situ loading test. Part 1: test configuration and execution, Tunn. Undergr. Space Technol. 26 (6) (2011) 764-777.

[16] W.Q. Ding, Q.Z. Yue, G.L. Tham, H.H. Zhu, C.F. Lee, T. Hashimoto, Analysis of shield tunnel, Int. J. Numer. Anal. Methods Geomech. 58 (2004) 57-91.

[17] R.G.A. deWaal, Steel Fibre Reinforced Tunnel Segments (ISBN90-407-1965-9) Delft University of Technology, The Netherlands, 1999.

[18] A.G. Kooiman, Modelling Steel Fibre Reinforced Concrete for Structural Design (Ph.D. thesis) Delft University of Technology, The Netherlands, 2000.

[19] A. Caratelli, A. Meda, Z. Rinaldi, Design according to MC2010 of fibre-reinforced concrete tunnel in Monte Lirio, Panama. Struct. Conc. 13 (3) (2012) 166-173. 
[20] M. Bakhshi, V. Nasri, Structural design of segmental tunnellinings, The 3rd International Conference on Computational Methods in Tunnelling and Subsurface Engineering, Ruhr University Bochum, Germany, 2013 (17-19 April).

[21] M. Bakhshi, V. Nasri, Guidelines and methods on segmental tunnel lining analysis and design - review and best practice recommendation, Proceedings of the World Tunnel Congress 2014, 2014 (May 9-15). (Iguassu Falls, Brazil).

[22] B. Chiaia, A.F. Fantilli, P. Vallini, Combining fibre-reinforced concrete with traditional reinforcement in tunnel linings, Eng. Struct. 31 (7) (2009) 1600-1606.

[23] B. Chiaia, A.P. Fantilli, P. Vallini, Evaluation of minimum reinforcement ratio in FRC members and application to tunnel linings, Mater. Struct. 42 (3) (2009) 339-351.

[24] O. Arnau, C. Molins, Experimental and analytical study of the structural response of segmental tunnel linings based on an in situ loading test. Part 2: numerical simulation, Tunn. Undergr. Space Technol. 26 (6) (2011) 778-788.

[25] P.E. Roelfstra, F.H. Wittmann, Numerical method to link strains oftening with failure of concrete, in: F.H. Wittmann (Ed.), Fracture Toughness and Fracture Energy of Concrete, Elsevier Science 1986, pp. 163-175.

[26] A.H.J.M. Vervuurt, C. Van del Veen, F.B.J. Gijsbers, F.B.I. Den Uijl, Numerical simulations of tests on a segmented tunnel lining, Procedings of the DIANA World Conference 2002, pp. 429-437 (Tokyo).

[27] T. Kasper, G. Meshke, A 3D finite element simulation model for TBM tunnelling in soft ground, Int. J. Numer. Anal. Methods Geomech. 1 (28) (2004) 1441-1460.

[28] EN 14651, Test method for metallic fibre concrete, Measuring the Flexural Tensile Strength (Limit of Proportionality (LOP), Residual), 2005.

[29] F. Levi, On minimum reinforcement in concrete structures, ASCE J. Struct. Eng. 111(12) (1985) 791-2796.

[30] L. Liao, A. de la Fuente, S. Cavalaro, A. Aguado, Design of FRC tunnel segments considering the ductility requirements of the MC 2010, Tunn. Undergr. Space Technol. 47 (3) (2015) 200-210.

[31] O. Hemmy, Brite Euram Program on Steel Fibre Concrete, Subtask: Splitting of SFRC Induced by Local Forces: Investigation of Tunnel Segments Without Curvature, University of Braunschweig, Germany, 2001.

[32] R. Burguers, Non-linear FEM Modelling of Steel Fibre Reinforced Concrete for the Analysis of Tunnel Segments in the Thrust Jack Phase (Mater thesis) Delft University of Technology, The Netherlands, 2006.

[33] R. Burgers, J.C. Walraven, G.A. Plizzari, G. Tiberti, Structural behaviour of SFRC tunnel segments during TBM operations, Underground Space the 4th Dimension of 
Metropolises: Proceedings of the World Tunnel Congress 2007 and 33rd ITA/AITES Annual General Assembly, 2007 (London, England).

[34] G. Tiberti, G. Plizzari, Structural behaviour of precast tunnel segments under TBM thrust actions, World Tunnelling Congress: Tunnels for a Better Life, WTC, Foz do Iguaçu, Brazil, 2014 (9-15 May, 2014).

[35] R. Breitenbücher, G. Meschke, F. Song, M. Hofman, Y. Zhan, Experimental and numerical study on the load-bearing behaviour of steel fibre reinforced concrete for precast tunnel lining segments under concentrated loads, FRC 2014 Joint ACI-fib In- ternational Workshop. Fibre Reinforced Concrete Applications, 2014 (24-25 July). (Montreal, Canada).

[36] M. Bakhshi, V. Nasri, Developments in design for fibre reinforced concrete tunnel segments, FRC 2014 Joint ACI-fib International Workshop. Fibre Reinforced Con- crete Applications, 2014 (24-25 July). (Montreal, Canada).

[37] L. Liao, A. de la Fuente, S. Cavalaro, A. Aguado, G. Carbonari, Experimental and analytical study of concrete blocks subjected to concentrated loads with an application to TBM-constructed tunnels, Tunn. Undergr. Space Technol. 49 (1) (2015) 295-306.

[38] UNE 83515, Fibre reinforced concrete, Determination of Cracking Strength, Ductility and Residual Tensile Strength. Barcelona Test, Spanish Association for Standardiza- tion and Certification, AENOR, 2010.

[39] S. Carmona, A. Aguado, C. Molins, Generalization of the Barcelona test for the toughness control of FRC, Mater. Struct. 45 (7) (2012) 1053-1069.

[40] P. Pujadas, A. Blanco, S. Cavalaro, A. de la Fuente, A. Aguado, New analytical model to generalize the Barcelona test using axial displacement, J. Civ. Eng. Manag. 19 (2) (2013) 259-271.

[41] ITATECH Activity Group Support, ITATECH design guidance for precast fibre reinforced concrete segments(July) Draft Report, 2015.

[42] EHE-08: Spanish Structural Concrete Standard. Annex 14: Recommendations for the Use of Fibre Reinforced Concrete.

[43] A. de la Fuente, A. Aguado, C. Molins, J. Armengou, Numerical model for the analysis up to failure of precast concrete sections, Comput. Struct. (2012) 106-107 (pp.: 105-14).

[44] EN 12350-2, Testing Fresh Concrete: Slump-test, 2009.

[45] EN 12350-8, Testing fresh concrete, Self-compacting Concrete: Slump-flow Test, 2010.

[46] EN 12350-7, Testing fresh concrete: Air content, Press. Meth. (2009).

[47] EN 12350-6, Testing Fresh Concrete: Density, 2009.

[48] EN 12390-3, Testing Hardened Concrete: Compressive Strength of Test Specimens, 2009. 
[49] J. Torrents, A. Blanco, P. Pujadas, A. Aguado, P. Juan-Garcia, M. Sanchez-Moragues,

[50] S.H.P. Cavalaro, R. Lopez, J. M. Torrents, A. Aguado, Assessment of fibre content and 3D profile in cylindrical SFRC specimens, Mater. Struct. (2014), http://dx.doi.org/ 10.1617/s11527-014-0521-2.

[51] A. Blanco, P. Pujadas, A. de la Fuente, S. Cavalaro, A. Aguado, Application of constitutive models in European codes to RC-FRC, Constr. Build. Mater. 40 (2013) 246259.

[52] A. Blanco, P. Pujadas, A. de la Fuente, S. Cavalaro, A. Aguado, Assessment of the fibre orientation factor in SFRC slabs, Compos. Part B 68 (2) (2015) 343-354 (2015).

[53] J.A.O. Barros, V.M.C.F. Cunha, A.F. Ribeiro, J.A.B. Antunes, Post-cracking behaviour of steel fibre reinforced concrete, Mater. Struct. 38 (1) (2005) 47-56.

[54] A. de la Fuente, R.C. Escariz, A.D. de Figueiredo, A. Aguado, Design of macro-synthetic fibre reinforced concrete, Constr. Build. Mater. 43 (2013) 523-532 (2013).

[55] RILEM TC 162-TDF, Test and design methods for steel fibre reinforced concrete. $\sigma-\varepsilon$ design method: final recommendation, RILEM Materials and Structures 36 (262) (2003) $560-567$.

[56] A. Meda, Z. Rinaldi, Steel fibers reinforcement for precast lining in tunnels with different diameters, FRC 2014 Joint ACI-fib International Workshop. Fibre Reinforced Concrete Applications 2014, pp. 522-531 (24-25 July). (Montreal, Canada). 